\title{
LA JUSTICIA CONSTITUCIONAL EN LA UNIÓN EUROPEA: LA CUESTIÓN PREJUDICIAL, EL CIUDADANO Y EL TRIBUNAL DE JUSTICIA DE LA UNIÓN EUROPEA
}

\author{
CONSTITUTIONAL JUSTICE IN THE EUROPEAN UNION: THE \\ PRELIMINARY RULING, THE CITIZEN AND THE COURT OF JUSTICE OF THE \\ EUROPEAN UNION
}

Augusto Aguilar Calahorro

Universidad de Granada - Granada - Espanha

\begin{abstract}
RESUMEN: En este trabajo trataré de analizar algunos elementos esenciales del sistema de justicia constitucional de la UE. Los Tratados de la Unión Europea han configurado elementos jurisdiccionales de naturaleza supranacional que nos pueden permitir elaborar un discurso sobre justicia constitucional en la UE. Si analizamos el contenido de los Tratados de la UE observamos que existen elementos constitucionales suficientes para afirmar la creación de una Constitución material. Desde esta perspectiva, en el ámbito europeo se han desarrollado algunas técnicas jurisdiccionales de interrelación entre tribunales nacionales ordinarios, tribunales constitucionales y el Tribunal de Justicia de la Unión Europea (TJ). De esta interrelación ha derivado el denominado "diálogo entre tribunales" que ha permitido la decantación de principios de carácter constitucional en el ordenamiento europeo (como los principios fundamentales de garantía y reconocimiento de los derechos fundamentales en la UE), y del que ha derivado el principal impulso a la constitucionalización de la Unión europea. Por ello, la metodología del Derecho constitucional europeo, sitúa en el centro de su estudio la relación entre tribunales nacionales y el TJ, el sistema jurisdiccional europeo, relación en la que la cuestión prejudicial tiene un papel fundamental.
\end{abstract}

PALABRA CLAVE: Justicia constitucional. Unión Europea. Tribunales nacionales.

ABSTRACT: In this paper I will try to analyze some key elements of the EU constitutional justice. The Treaties of the European Union have set jurisdictional elements of supranational nature that may allow us to develop a discourse on constitutional justice in the EU. If we analyze the content of the EU Treaties observe that there is sufficient to affirm the creation of a real constitutional elements. From this perspective, Europe have developed some jurisdictional techniques interrelation between ordinary domestic courts, constitutional courts and the Court of Justice of the European Union (TJ). This interrelationship has derived the so-called "dialogue between courts" which allowed the settling of constitutional principles in European law (as the basic principles of security and recognition of fundamental rights in the $\mathrm{EU})$, and it has led the main impetus to the 
constitutionalization of the European Union. Therefore, the methodology of the European constitutional law, is at the center of his study the relationship between national courts and the ECJ, the European judicial system, relationship in which the question has a fundamental role.

KEYWORDS: Constitutional Justice. European Union. National Courts.

\section{DERECHO CONSTITUCIONAL EUROPEO $Y$ JUSTICIA CONSTITUCIONAL}

En este trabajo trataré de analizar algunos elementos esenciales del sistema de justicia constitucional de la UE. Debo decir, desde el inicio, que es una tarea compleja, pues no existe una jurisdicción constitucional en la UE como tal. La razón principal es que tampoco existe una Constitución europea en sentido formal. A pesar de ello, los Tratados de la Unión Europea han configurado elementos jurisdiccionales de naturaleza supranacional que nos pueden permitir elaborar un discurso sobre justicia constitucional en la UE. Además, si analizamos el contenido de los Tratados de la UE (el Tratado de la Unión europea -TUE-, y el Tratado de Funcionamiento de la Unión Europea -TFUE-, denominados en su conjunto "Tratado de Lisboa") observamos que existen elementos constitucionales suficientes para afirmar la creación de una Constitución material ${ }^{1}$ (que cuenta desde 2007 con una Carta de Derechos Fundamentales).

Quisiera centrarme en este trabajo en dos elementos esenciales de la Constitución material europea que permiten armar un discurso sobre Justicia constitucional en la Unión: en primer lugar, los principios de primacía y eficacia directa; en segundo lugar, la cuestión prejudicial.

\footnotetext{
${ }^{1}$ DIEZ-PICAZO, L. M., "La naturaleza de la Unión Europea”, InDret, n. 4, 2008: «Así, si se observa la Unión Europea desde el punto de vista de sus fines y su funcionamiento, en lugar de hacerlo desde el punto de vista de su origen, deja de ser obvio que pertenezca exclusivamente al ámbito del derecho internacional: aunque formalmente es una organización internacional, sustancialmente es algo más». Esta idea se compone con los valores expuestos en el artículo 2 y 3.1 del TUE de 2007: "La Unión se fundamenta en los valores de respeto de la dignidad humana, libertad, democracia, igualdad, Estado de Derecho y respeto de los derechos humanos, incluidos los derechos de las personas pertenecientes a minorías. Estos valores son comunes a los Estados miembros en una sociedad caracterizada por el pluralismo, la no discriminación, la tolerancia, la justicia, la solidaridad y la igualdad entre mujeres y hombres". Artículo 3.1 "La Unión tiene como finalidad promover la paz, sus valores y el bienestar de sus pueblos".
} 
Dadas las particulares condiciones del proceso de integración europea, el análisis de estos elementos en perspectiva constitucional requieren de una metodología propia.

El estudio del Derecho europeo en perspectiva constitucional ha dado lugar a la aparición de una disciplina científica propia: el Derecho Constitucional Europeo. Esta nueva disciplina parte del estudio de la integración de la realidad constitucional nacional de los Estados con la UE. Es decir, de la existencia de una interacción entre el espacio europeo y el espacio estatal, y su estudio desde el ámbito específicamente constitucional ${ }^{2}$. El objeto del Derecho constitucional europeo, en sentido amplio, lo constituye la dialéctica entre los diversos espacios constitucionales en Europa (el espacio constitucional estatal, el espacio europeo, y el espacio regional o federal) y, el desarrollo de cada uno de esos espacios en perspectiva constitucional $^{3}$.

Desde esta perspectiva, en el ámbito europeo se han desarrollado algunas técnicas jurisdiccionales de interrelación entre tribunales nacionales ordinarios, tribunales constitucionales y el Tribunal de Justicia de la Unión Europea (TJ). De esta interrelación ha derivado el denominado "diálogo entre tribunales" que ha permitido la decantación de principios de carácter constitucional en el ordenamiento europeo (como los principios fundamentales de garantía y reconocimiento de los derechos fundamentales en la UE), y del que ha derivado el principal impulso a la constitucionalización de la Unión europea. Por ello, la metodología del Derecho constitucional europeo, sitúa en el centro de su estudio la relación entre tribunales nacionales y el TJ, el sistema jurisdiccional europeo, relación en la que la cuestión prejudicial tiene un papel fundamental

El motivo esencial de la peculiaridad del estudio constitucional del Derecho europeo es su naturaleza supranacional. Los Estados miembros, al ratificar los Tratados constitutivos de las Comunidades europeas, se auto limitaron y cedieron competencias soberanas a las Instituciones europeas. Ello conllevó un traslado de poder público legislativo, ejecutivo y judicial a un ámbito supranacional. Es decir, la

\footnotetext{
${ }^{2}$ HÄBERLE, P., “¿Tienen España y Europa una constitución?”, Fundación El Monte, Sevilla, 2004; ID. "Europa como Comunidad constitucional en Desarrollo", Revista de Derecho Constitucional Europeo (ReDCE), n.1, 2004, pp. 11-24.

${ }^{3}$ BALAGUER CALLEJÓN, F., "Presupuestos y perfiles metodológicos del Derecho Constitucional Europeo", en prensa. HÄBERLE, P., Derecho Constitucional Común Europeo, Revista de Estudios Políticos, n 79, 1993.
} 
configuración de un nuevo poder público supranacional europeo con capacidad para dictar por sí mismo actos normativos vinculantes ${ }^{4}$. Este poder público constituye un ente sui generis ${ }^{5}$, no identificable ni con las organizaciones de tipo internacionalista, ni con el concepto clásico de Estado-nación. Las Instituciones europeas, apoyadas en la cesión de soberanía realizada por los Estados en los Tratados europeos, producen Derecho (el denominado Derecho derivado). Este Derecho deriva directamente de los Tratados, hace depender su validez e interpretación, directamente de los Tratados europeos, y conforma un ordenamiento jurídico propio: autónomo ${ }^{6}$.

La naturaleza autónoma del ordenamiento europeo se observa en que, por un lado, los efectos que el Derecho europeo tiene en los ordenamientos nacionales plantean unas peculiaridades muy singulares respecto de los efectos tradicionales del Derecho internacional: el Derecho europeo se aplica con primacía y con eficacia directa sobre los ordenamientos nacionales. Pero además, los sujetos a los que regula, concediendo derechos e imponiendo obligaciones, son tanto los Estados miembros como los ciudadanos.

En mi opinión, el análisis de los principios de "primacía" y "eficacia directa", suponen el núcleo esencial del carácter constitucional de este ordenamiento jurídico autónomo que es el Derecho europeo. Lo cierto es que el análisis constitucional del ordenamiento europeo ha sido un camino muy transitado por la

\footnotetext{
${ }^{4}$ JOERGES, C. en el curso del desarrollo de sus tesis sobre el supranacionalismo deliberativo define el clásico Derecho internacional como un orden de relaciones interestatales basado en la voluntad de los Estados, por lo que resulta inconcebible una autoridad superior a la de los propios Estados. En este sentido es fácil entender porque el ordenamiento europeo es un ordenamiento supranacional y distinto al Derecho internacional. Ver Cfr. "Rethinking European law's supremacy ", EUI Working Paper Law, n.12, 2005.

${ }^{5}$ El carácter sui generis del Derecho europeo ha sido acuñado ya como un concepto propio de la ciencia jurídica europea. La definición más asentada del término sui generis, en este contexto, vendría a describir que la Unión Europea es un ente situado a medio camino entre un Estado federal y una organización internacional o asociación de estados soberanos, de este modo adquiere una estructura y funcionalidad intermedia entre ambas. Ver sobre el debate de su verdadera naturaleza híbrida: WEILER, J. H. H., "The promised Constitucional Land", King's College Law Journal, n. 12, 2001; ID. The Constitution of Europe: Do the new clothes have an Emperor?, and other essays on European Integration, Cambridge University Press, 1999. MACCORMICK, N., Questioning Sovereignity: law, state and Nation in the European Commonwealth, Oxford, Claredom Press, 1999. ID, "Beyond the Sovereign State", Modern Law Review, n. 56, 1993. En contra de considerar a la Unión Europea como una organización sui generis encontramos a WHAL, R., "¿Cabe explicar la Unión Europea mediante conceptos fundamentales de teoría del Estado?", Teoría y Realidad Constitucional, n. 18, 2006, pp. 105-129.

${ }^{6}$ Dictamen del Tribunal de Justicia 1/91, de 14 de diciembre de 1991.
} 
ciencia jurídica desde hace años ${ }^{7}$. La doctrina europea ya había afirmado en muchas ocasiones que el ordenamiento europeo estaba sufriendo una progresiva constitucionalización desde la aparición de estos dos principios fundacionales ${ }^{8}$. La primacía y la eficacia directa han encarnado las posibilidades científicas de reconstrucción del Derecho europeo desde las ideas de la "unidad del sistema normativo" y "la garantía de los derechos sustantivos" concedidos por el ordenamiento europeo a los ciudadanos. Por ello han sido observadas como dos herramientas útiles a la ordenación y limitación del poder público en el proceso de integración europea ${ }^{9}$. La primacía en tanto que principio útil para establecer las

${ }^{7}$ Respecto a las posibilidades constitucionales del Derecho europeo, la cuestión de la observación constitucional del ordenamiento europeo supuso un ferviente debate - aun abierto- en la doctrina alemana de los años noventa, basado esencialmente en una cuestión de perspectiva sobre el concepto "Constitución". Si en un primer momento, motivado por la Sentencia del Tribunal Constitucional Federal alemán sobre el Tratado de Maastricht (BVerfGE 89, 155 de 12 de octubre de 1993, 2 BvR 2134, 2159/92) se consideró que la UE no podía ser considerada como un ordenamiento constitucional ante la falta de un verdadero "Pueblo Europeo", requisito previo a la Constitución, posteriormente terminó por ganar la batalla la perspectiva según la cual la función de la Constitución no es otra que legitimar un dominio político institucionalizado, y la Unión Europea se puede distinguir como dominio político institucionalizado, por lo que debería abarcarse su estudio desde un prisma propio de la ciencia constitucional. Para un extraordinario resumen del debate me remito a AZPITARTE SÁNCHEZ, M., "Apuntes sobre el pensamiento de Peter Häberle en el contexto de la dogmática alemana", Revista de la Facultad de Derecho de la Universidad de Granada, 6,2003 , p. 362. Sobre la perspectiva estatalizante en la observación del ordenamiento europeo ver KIRCHHOFF, P., "The Balance of Powers between national and European institutions", European Law Journal, 5, n.3, 1999, pp. 225-242.

${ }^{8}$ Como ha expresado NETTESHEIM, «el derecho de la Unión adquiere significación constitucional no sólo porque pretende la primacía frente al Derecho nacional ordinario, sino, ante todo, por pretenderla frente al Derecho nacional constitucional», NETTESHEIM, M., "El significado constitucional de la primacía del derecho", Revista Española de Derecho europeo, n.6, 2008, p. 280. Sobre la actitud "constitucionalizante" del Tribunal de Justicia en su jurisprudencia sobre primacía, derechos fundamentales, poderes implícitos y efecto directo, me remito a MANCINI, G. F., "The Making of a Constitution for Europe", Common Market Law Review, Vol. 26, n.4, 1989, p. 596 y ss. Sobre la conformación del ordenamiento europeo sobre los principios de primacía y eficacia directa ver CHALMERS, D., HADJIEMMANUIL, C., MONTI, G., TOMKINS, A., "European Union Law", Cambridge University Press, Cambridge, 2007, pp. 45-50. Sobre la importancia de los principios de eficacia directa y primacía como elementos fundantes de la naturaleza del ordenamiento europeo ver el estudio, ya clásico, de DE WITTE, B., "Direct effect, supremacy, and the nature of the legal order", en CRAIG, P., y DE BURCA, G., The evolution of EU Law, Oxford University Press, Oxford, New York, 1999, pp. 177-210, que expone a modo de epílogo: «The principles of direct effect and supremacy, as presently formulated an accepted, continue to confirm the nature of EC law as that of branch of International law, albeit a branch with some unusual, quasi federal, blossoms».

9 JACOBSOHN, G. J., "Modern Jurisprudence and the Transvaluation of Liberal Constitutionalism", Journal of Politics, 47, n. 2., 1985, pp. 405 y ss. En doctrina española me remito a la obra de ARAGÓN REYES, M., Constitución, democracia y control, Instituto de investigaciones jurídicas, Serie Doctrina Jurídica, n. 88. México, 2002, pp. 81 y ss., «Efectivamente el control es un elemento inseparable del concepto de Constitución si se quiere dotar de operatividad al mismo, es decir, si se pretende que la Constitución se "realice" (...) El control no forma parte únicamente de un concepto "político" de Constitución, como sostenía Schmitt, sino de su concepto jurídico, de tal manera que sólo si existe control de la actividad estatal puede la Constitución desplegar su fuerza №. 42 | p. 69 - 119 | JAN - ABR 2014 
relaciones entre normas europeas y normas estatales, prescribiendo, en última instancia, las relaciones entre las Instituciones Europeas, como poder público europeo, y los poderes estatales. La eficacia directa como principio que representa las posibilidades de invocación por los ciudadanos ante los jueces nacionales de pretensiones subjetivas (derechos) fundadas en Derecho europeo.

En este sentido, un análisis jurídico sobre la Justicia constitucional en la Unión europea debería situar en un lugar central ambos principios ${ }^{10}$, pues la primacía y la eficacia directa se encuentran directamente relacionadas con las dos funciones básicas de la jurisdicción constitucional: la garantía de la supremacía de la Constitución (o en este caso, de la primacía de los Tratados y del Derecho derivado de ellos), y la tutela de derechos individuales.

Cuestión prejudicial y principios de primacía y eficacia directa conducen, en mi opinión, a una estructuración de las funciones constitucionales que hoy cumple el TJ como "Tribunal constitucional de la UE".

\section{EL PAPEL DEL TJ EN LA CONSTRUCCIÓN DE UN PARÁMETRO “EUROPEO” DE CONTROL DE LOS ACTOS DE LOS PODERES PÚBLICOS ESTATALES: PRIMACÍA Y EFICACIA DIRECTA.}

La Unión Europea comenzó su andadura como una más de las organizaciones internacionales con las que los Estados miembros han tratado de gobernar y regular los conflictos políticos, sociales y sobre todo económicos causados por la globalización. Pero pronto desarrolló un elemento distintivo: la atribución de competencias soberanas que realizan los Estados miembros mediante los Tratados europeos inviste a las Instituciones europeas del ejercicio de poder público (ejecutivo, legislativo y judicial). Aquí se encuentra el punto de

normativa, y sólo si el control forma parte del concepto de constitución puede ser entendida como norma».

${ }^{10}$ En relación con la conformación del ordenamiento europeo sobre los principios de primacía y eficacia directa ver CHALMERS, D., HADJIEMMANUIL, C., MONTI, G., TOMKINS, A., European Union law, Cambridge University Press, Cambridge, 2007, pp. 45-50. También en el mismo sentido ver el artículo del Abogado General del Tribunal de Justicia JACOBS, F.G., "The evolution of the European legal order", Common Market Law Review (en adelante CMLR), 41, 2, abril de 2004, pp. 303-316, espec. pp. 306 y 311. 
partida de la construcción de un ordenamiento supranacional muy particular ${ }^{11}$ que, en su progresivo desarrollo, ha adquirido algunos rasgos constitucionales propios.

Estos rasgos particulares han sido decantados, en su inmensa mayoría, por el Tribunal de Justicia de la Unión europea, mediante su competencia de interpretación de los Tratados comunitarios. Concretamente, el TJ desarrolló dos principios esenciales sobre la naturaleza supranacional de la UE: el principio de eficacia directa y el principio de primacía. Mediante ellos, las Comunidades europeas adquirían, una naturaleza distinta a las clásicas organizaciones internacionales: naturaleza supranacional. Distinguiéndose por dos elementos: la inserción de la ciudadanía como sujetos de Derecho europeo (eficacia directa) y la prevalencia aplicativa de Derecho europeo en caso de conflicto con el Derecho nacional (primacía).

A comienzos de los años 60 el TJ resolvió un asunto fundamental para el futuro del ordenamiento europeo: Van Gend en Loos ${ }^{12}$. El TJ respondía a una duda planteada por un juez nacional sobre la interpretación de los Tratados europeos. Se preguntaba concretamente acerca de la prohibición, establecida en art. 12 del Tratado de la Comunidad Económica Europea (TCEE), impuesta a los Estados miembros de crear nuevos derechos de aduana entre ellos. La cuestión prejudicial planteada derivaba de un proceso principal en el que un particular holandés (Van Gend en Loos) alegaba, ante el juez nacional, esta prohibición contra el Gobierno Alemán, por haberle impuesto el pago de un derecho sobre las importaciones de la empresa. El Juez estatal, ante la necesidad de interpretar el Derecho de los Tratados, y conforme a lo establecido en el antiguo artículo 177 TCEE $^{13}$ suspendió

${ }^{11}$ Con Miguel POIARES MADURO, podemos decir que la UE ha adquirido, a través de la cesión de competencias soberanas a las Instituciones, muchas de las tradicionales funciones de gobierno y, respecto de aquellas aun retenidas por los Estados, ejerce un creciente papel de supervisión, limitando los poderes de autogobierno de los Estados. Cfr. POIARES MADURO, M., "The importance of being called a constitution: Constitutional authority and the authority of constitutionalism", International Journal of Constitutional Law, n.3, 2005, pp. 2-3. En este sentido, aunque con fuertes connotaciones de ciencia económica, ver ALMIRANTE, C., "European Governance e Costituzione europea: fra revisiones tacita e 'anestesia' dei sistemi costituzionali degli Stati membri", en GAMBINO, S., y D'IGNAZIO, G., La revisione costituzionale e I suoi limiti. Tra teoria costituzionale, dirito interno ed sperienze straniere, Giappichelli, Milán, 2007, pp. 107 y ss.

${ }^{12}$ Sentencias del Tribunal de Justicia (SSTJ) de 5 de febrero de 1963, asunto Van Gend en Loos, C-26/62.

${ }^{13}$ Conforme al antiguo Artículo 177 del Tratado constitutivo de la Comunidad Económica Europea (actualmente 267 TFUE): "El Tribunal de Justicia será competente para pronunciarse, con carácter prejudicial: a) sobre la interpretación del presente Tratado; b) sobre la validez e interpretación de los actos adoptados por las instituciones de la Comunidad; c) sobre la interpretación de los 
el procedimiento principal, y mediante incidente procesal, preguntó al TJ, concretamente: «si el artículo 12 del Tratado CEE tiene efecto interno, o, dicho en otros términos, si los justiciables pueden invocar, basándose en dicho artículo, derechos individuales [frente a los Estados] que el Juez [nacional] deba proteger».

El TJ respondió que el Derecho europeo conforma un ordenamiento "autónomo", esto es, diverso del Derecho de los Estados y diverso del Derecho internacional ${ }^{14}$. Para el TJ, del "espíritu, el sistema y el tenor literal" de los Tratados $^{15}$ derivaba que el Derecho europeo, dadas sus atribuciones, suponía algo más que una simple voluntad de obligarse entre Estados. La vinculación de los Estados miembros a los Tratados se basa en la cesión del ejercicio de competencias soberanas a las Instituciones comunitarias, por lo tanto, de esta "cesión de soberanía" se desprendía que el Derecho europeo también vinculaba respecto de las relaciones entre los Estados y los ciudadanos, así como sobre las relaciones entre particulares, atendiendo a la idea de que la soberanía de los

estatutos de los organismos creados por un acto del Consejo, cuando dichos estatutos así lo prevean. Cuando se plantee una cuestión de esta naturaleza ante un órgano jurisdiccional de uno de los Estados miembros, dicho órgano podrá pedir al Tribunal de Justicia que se pronuncie sobre la misma, si estima necesaria una decisión al respecto para poder emitir su fallo. Cuando se plantee una cuestión de este tipo en un asunto pendiente ante un órgano jurisdiccional nacional, cuyas decisiones no sean susceptibles de ulterior recurso judicial de Derecho interno, dicho órgano estará obligado a someter la cuestión al Tribunal de Justicia".

${ }^{14}$ Con CHALMERS, D., HADJIEMMANUIL,C,. MONTI, G., y TOMKINS, A., decimos que «The European Union is not like other International organisations. This is true as a matter of political reality but, more importantly for our purposes, it is also true as a matter of law. What makes the EU different politically is the extent of its involvement in and influence over governance and regulation within nation-sates» en European Union Law, Cambridge, Cambridge University Press, 2007, p, 45 .

${ }^{15}$ Segundo considerando de Fondo de la Sentencia de 5.2.1963, del asunto C-26/62. En el cuarto párrafo de la sentencia sobre el fondo se dictamina que "esta concepción se encuentra confirmada por el Preámbulo del Tratado que además de a "los Gobiernos" se refiere a "los pueblos", y lo hace de forma más concreta mediante la creación de órganos en los que se institucionalizan poderes soberanos cuyo ejercicio afecta tanto a los Estados miembros como a sus ciudadanos". Ver BERRI, M., "Sull'efficacia delle sentenze della Corte di giustizia delle Comunità europee in materia di interpretazione giurisprudenziale autentica ai sensi dell'art. 177 del Trattato CEE", Giustizia civile, 1963, pp.1226-1231. CATALANO, N., "L'inserimento diretto delle disposizioni contenute nel Trattato istitutivo della Comunità economica europea negli ordinamenti giuridici degli Stati membri", II Foro padano, 1963, n. 5, pp.33-42. DURANTE, F., "Giudizio pregiudiziale, rapporti tra ordinamenti e principio di effettività nella recente giurisprudenza della Corte di giustizia delle Comunità europee", Rivista di diritto internazionale, 1963, pp.415-421. GORI, P., "Una pietra miliare nell'affermazione del diritto europeo", Giurisprudenza italiana 1963, n. $4^{\circ}$, pp.49-56. Más recientemente sobre el significado de esta sentencia ver DE WITTE, B., "The Continuous Significance of Van Gend en Loos", en POIARES MADURO, M., y AZOULAI, L., The Past and Future of EU Law. The Classics of EU Law Revisited on the 50th Anniversary of the Rome Treaty, Hart Publishing, 2010, pp.9-15. Igualmente MAYER, F. C., "Van Gend en Loos: The Foundation of a Community of Law", en POIARES MADURO, M., y AZOULAI, L., The Past and Future of EU Law..., op cit., pp.16-25. №. $42 \mid$ p. 69 - $119 \mid$ JAN - ABR 2014 
Estados democráticos emana de sus pueblos ${ }^{16}$. El TJ deduce que allí donde los Estados miembros se vinculan a las prohibiciones y obligaciones comunitarias, estos se entienden limitados en su poder normativo y ejecutivo también frente a los ciudadanos, lo que supone el derecho de los particulares a exigir su cumplimiento ante los jueces en defensa de sus prerrogativas ${ }^{17}$. Es decir, del Derecho europeo se desprenden derechos para los ciudadanos que se "incorporan directamente en su patrimonio jurídico"18 y que pueden hacerse valer por estos ante la jurisdicción nacional frente a violaciones por parte de los poderes públicos ${ }^{19}$.

Un año después, sobre esta base, el TJ establecería otro principio clave para la naturaleza de la integración europea: el principio de primacía en la

${ }^{16}$ El Tercer considerando sobre el fondo de la Sentencia Van Gend en Loss expresa "que el objetivo del Tratado CEE, que es el de establecer un mercado común cuyo funcionamiento afecta directamente a los justiciables de la Comunidad, implica que dicho Tratado constituye algo más que un Acuerdo que sólo crea obligaciones recíprocas entre los Estados contratantes".

${ }^{17}$ Los considerandos Octavo y Noveno de la Sentencia expresan que "el Derecho comunitario... al igual que crea obligaciones a cargo de los particulares, está también destinado a generar derechos que incorporan a su patrimonio jurídico; que esos derechos nacen, no sólo cuando el Tratado los atribuye de modo explícito, sino también en razón de obligaciones que el Tratado impone de manera perfectamente definida tanto a los particulares como a los Estados miembros y a las instituciones comunitarias".

${ }^{18}$ Señalar, con CHALMERS, en último término, que lo determinante en los derechos concedidos por el ordenamiento europeo que los particulares disfrutan no es el texto del Tratado, sino la interpretación que el TJ hace, basándose no tanto en las disposiciones de los Tratados como en el espíritu y el marco general bajo el que se fundó la Unión: la integración. Cfr. CHALMERS, D., European Union Law, cit. pp. 44- 57

19 La naturaleza de la eficacia directa, oscila entre su definición como la concesión de derechos a los particulares por el ordenamiento europeo que los jueces nacionales deben garantizar, y su definición como la posibilidad de invocar las normas de Derecho europeo bajo la obligación de los jueces nacionales de aplicarla. Es, según DE WITTE, B., "an obbligation to apply": "Direct effect is the obligation of a Court or another authority to apply the relevant provision of Community law". Ver DE WITTE, B., "Direct effect, Supremacy and the nature of the legal order", cit., pp. 184-188. En el Sexto considerando sobre el fondo el TJ se basa en el procedimiento de la cuestión prejudicial de interpretación (antiguo artículo 177 TCEE), planteada por los tribunales nacionales, para deducir que los Tratados han confirmado "al Derecho comunitario una eficacia susceptible de ser invocada por sus nacionales ante dichos órganos". Ver CHALMERS, D., et alt. European Union Law, cit., "The Court in Van Gend en Loos does not say this explicity, but it clearly suggest that the founding myth of the European Union may be legally constructed so that the European Union may be seen as an agreement between the peoples of Europe that binds their governments, and not simply as an agreement between the governments of Europe that binds its peoples», $p$. 50. En este sentido también JACOBS, F. G. "The evolution of the legal order", cit., «In the EC legal order, they [the economic freedoms], become rights which can be invoked by individuals and enterprises in the national courts - very often in practice not their own [European] courts, but the courts of the State against which they seek to enforce those rights. And the content of those rights is defined not by those ("foreign") courts, but, where necessary or appropriate, by the ECJ itself. Thus the rights are, tipically, broadly, construed», p. 308. Hay que señalar que para JACOBS la concesión de derechos es una consecuencia de la eficacia directa, pero no es idéntica al principio. La eficacia directa tiene otras consecuencias. Al inicio su contexto se limitaba al Mercado común, pero se encuentra estrechamente conectado con la fundación constitucional de la Comunidad. El efecto directo y la primacía han sido habitualmente considerados como constitutivos del carácter esencial del Derecho comunitario №. 42 | p. 69 - 119 | JAN - ABR 2014 
Sentencia Costa c. Enel (1964) ${ }^{20}$. En este asunto un ciudadano italiano, apoyándose en la sentencia anterior, se negaba al pago de la factura de la luz de la empresa de energía eléctrica estatal, alegando que la reciente ley sobre nacionalización de la industria eléctrica en Italia había contrariado determinadas disposiciones del Tratado $\mathrm{CEE}^{21}$. En este caso se preguntaba al TJ por el juez italiano, si un ciudadano italiano podía invocar una disposición de Derecho europeo contra la aplicación por los poderes públicos estatales de una norma nacional.

Como determinará el TJ, la invocación por un particular de una disposición de Derecho europeo ante la jurisdicción nacional para exigir su aplicación, se realiza, en la mayoría de los casos, contra una actuación de los poderes públicos estatales. Si el acto de los poderes públicos nacionales (acto normativo) pudiese contrariar a la norma europea, entonces el Derecho europeo se aplicaría en unos Estados miembros y no en otros, dando lugar a una aplicación no uniforme de las disposiciones europeas. Por eso el TJ señala que «la fuerza vinculante del Derecho comunitario no pude variar de un Estado a otro (...) sin que se ponga en peligro la realización de los objetivos de la Comunidad». El concepto clave es que los Tratados tienen como objetivo primordial la producción de un Derecho que debe ser aplicado de manera uniforme en todo el territorio de la Unión, por lo que sin una aplicación uniforme del Derecho europeo en todos los Estados la Comunidad europea misma carecería de sentido.

Dicho de otro modo, el TJ considerará que para la uniforme aplicación del Derecho europeo en todos los Estados miembros, será necesario "imponer" el Derecho comunitario sobre el Derecho nacional, es decir, la prevalencia del Derecho europeo sobre el Derecho nacional en caso de conflicto. El principio de primacía.

Desde estas dos particulares interpretaciones sistemáticas y teleológicas de los Tratados constitutivos de las Comunidades europeas, se desarrollan los principios de primacía y eficacia directa, y se estructura la específica naturaleza supranacional del Derecho europeo ${ }^{22}$. El TJ, especifica que la UE no sólo permite

\footnotetext{
${ }^{20}$ STJ de 15 de julio de 1964, asunto Costa contra ENEL, C-6/64.

${ }^{21}$ En concreto los antiguos artículos 102 sobre aproximación de legislaciones, 93 sobre concesión o modificación de ayudas de Estado, 53 prohibición de restricciones al establecimiento y 37 sobre la adecuación progresiva de los monopolios de Estado a la CEE.

${ }^{22}$ Sobre el concepto de supranacionalidad, la obra clásica de WEILER, J.H.H., II sistema comunitario europeo, II Mulino, Bolonia, 1985, p. 41 ss. Para el autor hablar de supranacionalismo
} 
la regulación de las relaciones entre Estados, también impone límites particulares a la actividad interna y externa de los Estados concediendo derechos a los ciudadanos $^{23}$.

La configuración de la naturaleza supranacional de la UE despliega una dimensión constitucional propia. Por un lado, los ciudadanos se convierten en sujetos de Derecho europeo, sujetos que pueden invocar derechos fundados en disposiciones europeas contra los actos del poder público estatal. Por otro lado, se desarrollan mecanismos jurídicos supranacionales que han contribuido a cumplir con uno de los elementos básicos de la justicia constitucional: la limitación del poder por medio del control de la compatibilidad de los actos del poder público estatal con un parámetro normativo de referencia (en este caso, los Tratados). Control y limitación en garantía de los derechos de los ciudadanos.

En conclusión, debe retenerse la importancia que juegan los principios de primacía y eficacia directa en la configuración del Derecho europeo como ordenamiento supranacional y, en consecuencia, cómo permiten la apertura de una dimensión constitucional de la UE si se observan desde su funcionalidad para la limitación del poder estatal y la garantía de derechos europeos de los ciudadanos.

en un sentido literal de "sobre y bajo el estado nacional" nos da una noción del sistema europeo demasiado anticuada y general, por el contrario, el sistema europeo se compone de piezas y trozos de la soberanía estatal. Siguiendo una concepción del modelo federal, la Unión presenta una tensión entre "el todo y las partes", las Instituciones de la Unión y los Estados. Con DíEZ PICAZO decimos que la UE es un ente supranacional en un doble sentido: en sentido normativo, porque muchas de sus normas vinculan directamente a las autoridades nacionales y a los particulares; y en un sentido decisional, porque la aprobación de dichas normas no está necesariamente sometida a la regla de la unanimidad -la tendencia ha venido siendo la de reducir progresivamente las materias en que se exige la decisión unánime- y porque en el procedimiento participan actores distintos de los representantes de los Gobiernos. Cfr. DÍEZ-PICAZO, L. M. "La naturaleza de la Unión Europea", cit.

${ }^{23} \mathrm{La}$ interpretación extensiva realizada en sus sentencias por el TJ en relación con el Mercado Común, ha sido fundamental en el desarrollo del Derecho europeo. Las cuestiones prejudiciales de interpretación planteadas al TJ por los jueces nacionales han girado esencialmente en torno a las "libertades económicas" y a su percepción como auténticos derechos fundamentales. El reconocimiento de las libertades fundamentales como derechos fundamentales se condensa en la interrelación de diversos elementos entre los que destaca el principio de eficacia directa. La evolución de esta visión ha llegado a su culmen a través del reconocimiento y la positivización en la Carta de Derechos Fundamentales de la Unión Europea introducida en el TUE a través del artículo 6.1, en cuyo título $V$ se introducen los derechos de Libertad de circulación y de residencia, derechos derivados de la Libertad Fundamental de Circulación de Trabajadores. En un sentido casi idéntico en el Tratado de Funcionamiento de la Unión Europea (TFUE) se enuncia en los artículos 20.2 y 21.1 los derechos de libertad de circulación y residencia. Fue el TJ el que afirmó que las libertades de circulación y de servicios deben ser interpretadas como libertades fundamentales en las Sentencias Reyners, de 21 de junio de 1974, C- 2/74; y Walrave, de 12 de diciembre de 1974 , C-36/74. №. 42 | p. 69 - 119 | JAN - ABR 2014 


\section{UNIÓN DE DERECHO Y JUSTICIA CONSTITUCIONAL: LIMITACIÓN DEL PODER DEL ESTADO EN GARANTía DE DERECHOS DE LOS CIUDADANOS}

Como hemos dicho, la determinación del TJ en los asuntos Van Gend en Loos en 1963 y Costa c. ENEL en 1964, caracterizó al Derecho europeo como un ordenamiento jurídico de naturaleza supranacional: "el Tratado de la CEE creó un ordenamiento jurídico propio, integrado en el sistema jurídico de los Estados miembros desde la entrada en vigor del Tratado, y que vincula a sus órganos jurisdiccionales" ${ }^{24}$. Con esta determinación el TJ no sólo afirmó la autonomía del Derecho comunitario respecto del Derecho internacional, sino también que el Tratado de la Comunidad Europea no podía ser interpretado y aplicado como un simple tratado internacional, sino que requería su observación como una auténtica Carta Constitucional de las Comunidades ${ }^{25}$.

Será a partir de los años ochenta, cuando el TJ haga explícita su idea de la constitucionalización del orden europeo a través de la interpretación de los Tratados. En la Sentencia Parti écologiste- Les Verts, C-294/83, de 23 de abril de 1986, declarará: "la Comunidad Económica Europea es una Comunidad de Derecho, en la medida en que ni sus Estados miembros ni sus Instituciones pueden sustraerse al control de la conformidad de sus actos con la carta constitucional fundamental que es el Tratado". Y de forma definitiva en el Dictamen del TJ 1/91: "El Tratado CEE aunque haya sido celebrado en forma de convenio internacional, no por ello deja de ser la carta constitucional de una Comunidad de

\footnotetext{
${ }^{24}$ Sentencia Costa c. ENEL, décimo considerando sobre el fondo.

${ }^{25}$ DIEZ-PICAZO, L. M., "La naturaleza de la Unión Europea", cit., Como señala el autor "Sobre esta premisa, el Tribunal de Justicia se ha apartado a menudo de los criterios establecidos en el derecho internacional". Así podemos citar las SSTJ: Comisión c. Luxemburgo y Bélgica , C- 90 y 91/63, de 13 de noviembre de 1964, donde refuta en el ámbito europeo el "Principio de reciprocidad"; Comisión c. Francia, C- 7/71, de 14 de diciembre de 1971, donde señala que a diferencia de lo que ocurre en el derecho internacional, la falta de ejercicio de las competencias comunitarias no supone la caducidad de las mismas, ya que la limitación de la soberanía de los Estados miembros es definitiva; Reino Unido c. Consejo, C-68/86, de 23 de febrero de 1988, donde sostiene que los Tratados constitutivos no pueden ser tácitamente modificados por vía consuetudinaria, ya que las instituciones comunitarias carecen de un poder de disposición sobre ellos. "Aquí no sólo hay una afirmación de la rigidez de los Tratados constitutivos -que únicamente pueden ser modificados por el procedimiento de revisión previsto por ellos mismos, hoy contenido en el art. 48 TUE- sino también, al recordar que las instituciones comunitarias están plenamente sometidas a aquéllos, un eco de la distinción entre poder constituyente y poderes constituidos» dirá Díez-picazo.
} 
Derecho"26. La consideración de la Unión Europea como Comunidad de Derecho implicó equiparar la fuerza de los Tratados constitutivos a la más elevada manifestación del rule of law a nivel nacional, es decir, no sólo como principio de legalidad sino también como principio de constitucionalidad ${ }^{27}$.

Los principios de primacía y eficacia directa permitieron, entonces, la consideración de la Unión Europea como una "Unión de Derecho"28, es decir, la transferencia del carácter del Estado de Derecho al ordenamiento jurídico de la Unión. Esta consideración sugiere que todos los poderes públicos y los particulares se encuentran sometidos al Derecho nacido de los Tratados: el sometimiento al Derecho europeo de las Instituciones europeas, los poderes públicos nacionales y los ciudadanos de todos los Estados miembros. Con esta transferencia se cumple una de las premisas básicas de cualquier ordenación constitucional de Derecho: la constatación de que el poder se encuentra limitado por el Derecho ${ }^{29}$.

Como afirma POIARES MADURO el análisis del "constitucionalismo europeo" debe ser entendido, en consecuencia, como una «teoría normativa que comprende el conjunto de procedimientos y reglas que identifican, disciplinan y gobiernan al poder ${ }^{30}$ ». En el marco de la Unión de Derecho, esta regulación e identificación del poder conlleva necesariamente la imposición de límites infranqueables de éste frente a los ciudadanos. Estos límites se establecen en forma de procedimientos de tutela y garantía de los derechos de los ciudadanos

26 Puede destacarse también uno de los primeros reconocimientos por parte de un Tribunal Constitucional del carácter constitucional "en cierto sentido" de los Tratados, la Ordenanza del Tribunal Constitucional Federal Alemán BverfGE, 22, 293, EcuG-Verondnuger, de 18 de octubre de 1967, ordenanza donde el TCFA califica al Tratado CECA como la Carta Constitucional de la Comunidad.

27 DIEZ PICAZO, L. M., cit..

28 STJ de 23 de abril de 1986, asunto Los verdes v. Parlamento europeo,C-294/83, "es una Comunidad de Derecho en la medida en que ni sus Estados miembros ni sus instituciones pueden sustraerse al control de la conformidad de sus actos con la carta constitucional fundamental que constituye el Tratado". En doctrina, el término "Comunidad de derecho" fue acuñado en el ámbito de la UE por Walter HALLSTEIN, Der unvollendete Bundesstaat. Europäische Erfahrungen und Erkenntnisse, Düsseldorf, 1969. Ver STOLLEIS, M., "Europa como Comunidad de Derecho", Historia Constitucional, n. 10, 2009. Consultado en http://www.historiaconstitucional.com pp. 475484.

29 BALAGUER CALLEJÓN, F., "Niveles y técnicas internacionales e internas de realización de los derechos en Europa. Una perspectiva constitucional", ReDCE, n.1, 2004, pp. 25-46, e igualmente en "Livelli istituzionali e tecniche di riconoscimento dei diritti in Europa. Una prospettiva costituzionale", ROLLA, G., Tecniche di garanzia dei diritti fondamentali, G. Giappichelli Editore, Turín, 2001, pp. 113-130

30 POIARES MADURO, M., "From Constitutions to Constitutionalism: A Constitutional Approach for Global Governance”, en LEWIS, D., (coord.), Global Governance and the Quest for Justice, Vol I, Hart Publishing, Oxford, 2006. 
derivados de los Tratados, que al tener eficacia directa y primacía, se refuerzan frente a los actos de poder público nacional.

La exigencia de trasladar los mecanismos propios del Estado de Derecho al ordenamiento comunitario se advierte en la realización de la integración también desde el punto de vista de sus fuentes. Los Tratados y el Derecho derivado de las Instituciones se integran de manera automática en los ordenamientos nacionales correspondiendo a los poderes públicos de los Estados la implementación y ejecución de las normas europeas. En este momento la limitación de poder impuesta a los Estados por los Tratados resulta un imperativo, al ser el instante en que los derechos concedidos a los ciudadanos por las normas europeas se hacen efectivos $^{31}$. Es así como los principios de primacía y eficacia directa vinculan al poder público estatal y promueven la Comunidad de Derecho puesto que, en esencia, actúan como una obligación de los Estados miembros de aplicar y conceder eficacia a las normas europeas en los ordenamientos nacionales, desplazando si fuera necesario las normas nacionales contrarias al Derecho nacido de los Tratados europeos ${ }^{32}$.

La primacía y la eficacia directa vienen así a contribuir a la estructuración de un sistema de justicia constitucional en la UE, pues permiten una comprensión del ordenamiento europeo como límite a la actuación del poder del Estado (también legislativo) en el sentido de establecer una adecuada tutela jurídica de los derechos de los ciudadanos frente a la actuación del Estado inconsistente con las normas europeas.

Como presagió tempranamente el TJ, la forma más efectiva de garantía de la vinculación de los poderes públicos nacionales al Derecho europeo es permitir a cada uno de los ciudadanos fundar sus pretensiones en el ordenamiento europeo e

${ }^{31}$ ALONSO GARCÍA, R., Las sentencias básicas del Tribunal de Justicia de las comunidades Europeas, Civitas, $3^{\underline{a}}$ Ed., Navarra, 2006, pp. 27-28. En el mismo sentido de reparto del poder y limitación del mismo, considera el trasfondo constitucional material de los Tratados "insuficiente",

${ }^{32}$ Esta aplicación es una verdadera obligación de carácter vinculante. Me remito al artículo 4.3 del Tratado de la Unión Europea: "Conforme al principio de cooperación leal, la Unión y los Estados miembros se respetarán y asistirán mutuamente en el cumplimiento de las misiones derivadas de los Tratados. Los Estados miembros adoptarán todas las medidas generales o particulares apropiadas para asegurar el cumplimiento de las obligaciones derivadas de los Tratados 0 resultantes de los actos de las instituciones de la Unión. Los Estados miembros ayudarán a la Unión en el cumplimiento de su misión y se abstendrán de toda medida que pueda poner en peligro la consecución de los objetivos de la Unión." 
invocar sus normas ante las jurisdicciones nacionales ${ }^{33}$. Los procedimientos de invocación del Derecho europeo se encuentran en el corazón de la Justicia constitucional europea, puesto que tienen dos resultados:

- Por un lado, con la posibilidad de que los ciudadanos invoquen pretensiones fundadas en disposiciones europeas, se garantiza el cumplimiento de las obligaciones de los Estados derivadas del ordenamiento comunitario, evitando que tomen eficacia disposiciones nacionales contrarias a lo establecido en la "Carta Constitucional de la UE".

- Por otro lado se garantizan la tutela de los derechos concedidos a los particulares por las disposiciones de origen europeo. $Y$ al tiempo, los procedimientos de invocación del Derecho europeo ante la jurisdicción nacional por los ciudadanos, abren una vía jurídica que puede contribuir a la legitimación de la Unión Europea. Con legitimación me refiero al papel de los ciudadanos en el desarrollo de la "infraestructura social" ${ }^{34}$ y el éxito del ordenamiento europeo como Derecho, destinado a resolver conflictos provocados por las relaciones globales (a nivel europeo). Con LAENAERTS podemos afirmar que cualquier ordenamiento conformado con normas legales que prometen una realidad que los ciudadanos no pueden disfrutar en la práctica pierde eventualmente toda credibilidad, por ello "una más efectiva y orientada aplicación del Derecho europeo puede [además] ayudar a restaurar la fe en la razón de ser de la Unión. Una aproximación más uniforme a la

${ }^{33}$ En el sentido de la jurisprudencia Van Gend en Loss y Costa c. Enel. Doctrinalmente me remito a la obra de WARD, A., Judicial Review and the Rights of Private Parties in EC Law, OUP, 2000, concretamente p. 158.

34 Para BOGDANDY, las dificultades para realizar una síntesis sobre el estado actual del debate científico-jurídico del Derecho europeo no se debe a su carácter autónomo, sino a «la función primaria de la ciencia jurídica como ciencia práctica, que consiste en el "cuidado" de una importante "infraestructura" social, principalmente en la producción y garantía de la transparencia y coherencia del Derecho". La garantía de coherencia y transparencia, según el autor, se encuentra en el propio dinamismo de la integración, es decir, en la creación de la infraestructura jurídica conforme las condiciones y situaciones de la integración lo requieran: parafraseando a Robert Schumann expresa que «en la solución de problemas prácticos es más fácil encontrar el consenso que en la proposición de proyectos teóricos» con estas últimas palabras se inició la historia de la integración europea. BOGDANDY, A., "Notas sobre la ciencia del Derecho europeo: contexto, debates y perspectivas de desarrollo de la teoría general del Derecho de la Unión Europea desde el punto de vista alemán", Teoría y realidad constitucional, № 5, 2000, pp. 304305. Citando de nuevo a JACOBS lo increíble de la declaración de la primacía es su aplicabilidad por el juez nacional, puesto que la jerarquía de los tratados sobre el derecho nacional ya era una cualidad conocida. Lo novedoso, desde el punto de vista de la autonomía del Derecho europeo, es que la primacía puede ser aplicada en la resolución de un caso concreto a favor del Derecho europeo. Cfr. JACOBS, F. G., "The Evolution of the European legal order", cit. pp. 313-314. №. 42 | p. 69 - 119 | JAN - ABR 2014 
invocación del Derecho europeo puede contribuir a fortalecer la legitimidad de la Unión"35.

Los límites a la soberanía estatal establecidos en los Tratados europeos, junto a los principios establecidos por la jurisprudencia del TJ, permiten la creación de garantías jurisdiccionales a través de las cuales los ciudadanos puedan invocar derechos fundados en el ordenamiento europeo y forzar el cumplimiento de las obligaciones y límites impuestos a los Estados. De la firmeza de tales mecanismos de limitación del poder estatal y de garantía de derechos de los ciudadanos, depende gran parte de la existencia de una justicia constitucional en la Unión europea $^{36}$.

\section{JUEZ NACIONAL COMO JUEZ EUROPEO}

Los principios de primacía y eficacia directa, como se han visto, son dos elementos esenciales de la Constitucionalización del ordenamiento europeo (como Comunidad Constitucional de Derecho), pero también constituyen principios destinados al juez nacional para seleccionar la norma aplicable al caso concreto. Son principios de aplicación del Derecho europeo, pues es obligación del juez ordinario (poder público nacional) dotar de eficacia directa al Derecho europeo y concederle primacía en caso de conflicto con el Derecho nacional ${ }^{37}$.

El relevante papel del juez nacional en el momento de aplicación del Derecho europeo en el ámbito interno convierte a aquel en "juez europeo ${ }^{38 "}$.

${ }^{35}$ LAENARTS, K., y CORTHAUT, T., "Of birds and hedges: the role of primacy in invoking norms of EU Law", European Law Review, n.31, 2006, p. 287 y ss.

${ }^{36}$ Para WHAL "el Estado de Derecho en el contexto europeo implica la existencia de normas vinculantes que se aplican de manera uniforme y que protegen los derechos individuales" ver WHAL, R., "¿Cabe explicar la Unión Europea mediante conceptos fundamentales de teoría del Estado?", cit., pp. 105-129. Expondré más adelante la importancia de la aplicación uniforme y la virtualidad de la primacía en sus resultados.

${ }^{37}$ La sentencia del TJ Simmenthal, que resuelve el asunto C- 106/77, con fecha de 9 de marzo de 1978, es la consecuencia directa de la aplicación del mandato Costa c. ENEL. En ella el TJ determina que en caso de conflicto entre una norma nacional con rango de ley y una disposición de Derecho europeo, el juez nacional debe obviar la eficacia de la ley nacional y aplicar la norma europea para resolver el caso concreto.

${ }^{38}$ Ver FERNÁNDEZ SEGADO, F., "El juez nacional como juez comunitario europeo de Derecho común. Las transformaciones constitucionales dimanantes de ello", Cuestiones Constitucionales, n.13, 2005, pp. 57 y ss. Igualmente ALONSO GARCíA, R., El juez español y el derecho comunitario, Tirant lo Blanch, Valencia, 2003; ID. "Juez nacional como juez europeo a la luz del Tratado constitucional”, Conferencia presentada en la Universidad Carlos III de Madrid, del 5 al 7 de septiembre de 2004, en el ámbito del congreso «The national constitutional reflection of 
El problema fundamental al que se enfrenta el proceso de integración europea es que su objetivo primordial, la progresiva "unión entre los pueblos de Europa", se realiza a partir del desarrollo y la aplicación uniforme del Derecho europeo. Este Derecho pretende integrarse en cada uno de los ordenamientos jurídicos de los distintos Estados miembros con eficacia plena y uniforme. Sin embargo, la producción y promulgación de este Derecho atiende a la voluntad de entes distintos de aquellos que finalmente tendrán que aplicarlo en cada ordenamiento estatal ${ }^{39}$. Son los poderes públicos de los Estados los que tienen el deber de implementar el Derecho europeo en el nivel nacional, y en su aplicación e implementación pueden aparecer diversos obstáculos que condicionen su eficacia y trunquen la finalidad del proceso de integración. Para evitar las posibles inconsistencias entre los actos de los poderes públicos y el efecto útil de las normas dictadas por las Instituciones europeas apareció el principio fundamental de la primacía del Derecho europeo. La primacía se ha desarrollado en los últimos años en torno a las posibilidades del juez nacional de desaplicar la disposición nacional contraria al Derecho europeo. El juez nacional ordinario se convierte en el principal valedor de la primacía del Derecho europeo y, por lo tanto, en el primer garante de los límites impuestos por éste a los Estados y de los derechos concedidos por el mismo a los ciudadanos.

En el momento de garantía de la eficacia del Derecho europeo, se destaca muy particularmente el papel de los jueces y tribunales nacionales, por su doble carácter de jurisdicción nacional y jurisdicción europea. En la jurisdicción nacional y en el proceso ante el tribunal la aplicación del Derecho europeo alcanza uno de los momentos más delicados de encuentro entre el ordenamiento europeo y el estatal. En este momento el juez tiene la obligación de componer la norma que resuelva un caso concreto, composición en la que a menudo debe agregar disposiciones

European Union Constitucional Reform». También RODRÍGUEZ IGLESIAS, G. C., y BARQUERO, J., "Funciones constitucionales del Tribunal de Justicia de las Comunidades Europeas", Revista Fundamentos. Cuadernos Monográficos de teoría del Estado, Derecho público e historia constitucional, n.4, 2006. MARTíNEZ SIERRA, J. M., La recepción constitucional del derecho comunitario, Tirant lo Blanch, Valencia, 2007, espec. pp. 88 y ss. De todos ellos es destacable la idea de que la doctrina Simmenthal y la actitud del juez nacional en la activación del principio de primacía fue recepcionado en España a través de la Sentencia del Tribunal Constitucional Español 28/1991.

39 Debe entenderse aplicación en sentido amplio, incluyendo los procesos de transposición del Derecho europeo y su implementación. Ver BERRY, E., HARGREAVES, S., European Union Law, OUP, Oxford, 2007, p. 73. 
nacionales y disposiciones europeas. En este momento el juez debe realizar declaraciones sobre la conformidad o disconformidad de una conducta con el Derecho nacional y, en incontables ocasiones, con el Derecho europeo, vinculando a la calificación de la conducta consecuencias jurídicas. En el proceso de calificación de la conducta de un sujeto en el caso concreto y en la elección de la norma aplicable, el juez nacional debe conjugar y sopesar disposiciones de ambos ordenamientos así como sus instrumentos de garantía. En este momento los instrumentos de garantía específicos del ordenamiento europeo —primacía y eficacia directa- adquieren una relevancia esencial para determinar la norma aplicable.

Si el ordenamiento europeo debe ser implementado de manera uniforme por todos los poderes públicos de los EE.MM (conforme a la primacía) y, en último lugar, el juez nacional debe resolver las inconsistencias que impidan su eficacia, esto no sólo significa que la disposición comunitaria deba prevalecer sobre la nacional, sino que aquella debe tener el mismo significado y efecto en todos los EE.MM.

La aplicación uniforme del Derecho europeo por los poderes públicos no se refiere sólo al contenido material de las disposiciones de la UE, sino también, e incluso de modo especial, a la determinación uniforme de su alcance, de sus efectos y de su eficacia ${ }^{40}$. Este alcance y eficacia, si realmente pretende ser uniforme, debe ser determinado por un único órgano encargado de dar uniformidad a las disposiciones de Derecho europeo, el Tribunal de Justicia de la Unión Europea $^{41}$. Y esta tarea será cumplida a través del procedimiento de la cuestión prejudicial donde interaccionan y "dialogan" los jueces nacionales encargados de seleccionar la noprma aplicable a un caso (entre disposiciones europeas y nacionales) y el TJ, encargado de analizar la validez de las disposiciones europeas y de interpretar los Tratados.

\footnotetext{
40 PESCATORE, P., "The doctrine of «Direct effect»: An infant Disease of Community Law", European Law Review, 1983, p. 155-164.

${ }^{41}$ BERRY, E., HARGREAVES, S., European Union Law, OUP, Oxford, 2007, p. 73. Recordemos que según el TCE "El Tribunal de Justicia y el Tribunal de Primera Instancia garantizarán, en el marco de sus respectivas competencias, el respeto del "Derecho» en la interpretación y aplicación del presente Tratado" Art. 220 TCE.
} 


\section{EL TRIBUNAL DE JUSTICIA DE LA UNIÓN EUROPEA Y LA CUESTIÓN PREJUDICIAL: FUNCIONES}

Conforme al artículo 19 del TUE, se dispone que «el Tribunal de Justicia garantizará, en el marco de sus respectivas competencias, el respeto del Derecho en la interpretación y aplicación del presente Tratado». El papel del TJ es, pues, fundamental para garantizar el «respeto del Derecho» europeo, con mayúsculas, en el momento de su aplicación por los poderes públicos de los EE.MM.

Esta función de garantía del "Derecho" va más allá de las de cualquier juez o tribunal nacional puedan desempeñar, incluso de las de cualquier tribunal constitucional. $Y$ es que el TJ garantiza el Derecho en un contexto normativo y ordinamental muy particular. El Derecho europeo es un ordenamiento de integración, que carece de una Constitución formal. En la teoría constitucional, la Constitución debe entenderse como factor de integración, pues cumple, por un lado, una función de determinación de valores que sean aceptados por la sociedad (en el plano social de la integración), por el otro, una función de configuración y coordinación entre sistemas (plano normativo) ${ }^{42}$. En el proceso de integración europea, por ser un proceso de integración de ordenamientos, ambas funciones son esenciales. Pero al no existir una verdadera Constitución se exige al TJ un esfuerzo adicional a la hora de dirimir sobre la ordenación de las fuentes europeas y su eficacia, sobre su interpretación y validez. EI TJ, se convierte así, en factor protagonista de la integración ${ }^{43}$.

Para demostrar lo que se acaba de decir, basta recordar la determinación con la que definió al Derecho europeo como ordenamiento autónomo, y cómo ha creado y desarrollado los principios de primacía y eficacia directa sin que nada se dispusiese expresamente en los Tratados.

\footnotetext{
${ }^{42}$ GRIMM, D., "Integración por medio de la constitución, propósitos y perspectivas en el proceso europeo de constitucionalización", Teoría y Realidad constitucional, n. 15, 2004, pp. 53-69

${ }^{43}$ BALAGUER CALLEJÓN, F., "Los Tribunales constitucionales en el proceso de integración europea", op. cit. El autor afirma que el TJ desarrolla sus funciones a falta de un auténtico contexto constitucional por la falta de los tres agentes esenciales sobre los que se construye el orden constitucional: Constituyente, legislativo y jurisdiccional; por lo que debe realizar una función constituyente estableciendo los propios principios fundamentales de articulación del ordenamiento comunitario europeo pero donde, a la vez, esa función constituyente tiene una vocación legislativa. Ver también, del mismo autor: "Livelli istituzionali e tecniche di riconoscimento dei diritti in Europa. Una prospettiva costituzionale", en ROLLA, G. C., Tecniche di garanzia dei diritti fondamentali, Giappichelli Editore, Torino, 2001, pp. 113-130. Versión española en Revista de Derecho Constitucional Europeo, n 1, 2004, pp. 25 a 46.
} 
La jurisprudencia del TJ con la que ha ido conformando estos caracteres del ordenamiento europeo se han realizado, en su mayoría, mediante un instrumento procedimental clave en la función del TJ: las cuestiones prejudiciales de validez o interpretación del Derecho europeo planteadas por los jueces nacionales cuando aplican disposiciones comunitarias.

El artículo 19.3 del TUE dispone también que el "Tribunal de Justicia de la Unión Europea se pronunciará, de conformidad con los Tratados: (...) con carácter prejudicial, a petición de los órganos jurisdiccionales nacionales, sobre la interpretación del Derecho de la Unión o sobre la validez de los actos adoptados por las instituciones". La cuestión prejudicial se configura en el TUE como un incidente procesal destinado a resolver las dudas sobre la interpretación o la validez del Derecho comunitario a aquellos órganos jurisdiccionales de los Estados miembros sobre una disposición europea con ocasión de su aplicación. Si se plantea una duda al juez o tribunal nacional, éste puede suspender el procedimiento jurisdiccional y elevar una cuestión al TJ sobre la interpretación del Derecho europeo. Por lo tanto, la cuestión prejudicial es un instrumento esencial para los jueces nacionales de los Estados miembros en ese delicado momento en el que deliberan sobre la base de dos ordenamientos (o más), e implementan el Derecho europeo al componer la norma en los casos concretos. Es el incidente procesal que les permite acudir al TJ para aclarar el sentido o la validez de las disposiciones europeas y componer así, integrando disposiciones estatales y europeas, la norma que resuelva el caso concreto en sede nacional.

Como en su momento expuso LECOURT, presidente del TJ durante el periodo de 1967 a 1976, "la piedra angular de la Comunidad no era tan sólo una misma norma común, sino que esa norma fuera interpretada y aplicada de igual manera en toda su extensión territorial por los tribunales nacionales ${ }^{44 "}$. La razón de ser de la cuestión prejudicial se encuentra precisamente en el propósito de asegurar que el Derecho comunitario sea aplicado de manera uniforme en todos

\footnotetext{
${ }^{44}$ LECOURT. P., "Le rolè inificateur du juge dans la communauté", AA.VV., Etudes de Droits des Communautés Européenes (mélange offerts à Pierre-Henri Teitgen), París Pedone, 1984.
} 
los Estados miembros ${ }^{45}$. La cuestión prejudicial es, garantía procedimental de la uniformidad en la interpretación y aplicación del Derecho europeo ${ }^{46}$.

Pero como se ha dicho al comienzo de este epígrafe, la cuestión prejudicial, al mismo tiempo, contribuye a que el TJ desarrolle su labor de garante de la eficacia y coherencia del ordenamiento europeo, su labor de integración. La cuestión prejudicial es la "joya de la corona" de la jurisdicción europea ${ }^{47}$, pero no sólo por el poder «uniformador» en la aplicación del Derecho, sino principalmente, por su poder «conformador» de un ordenamiento constitucional ${ }^{48}$.

Por ello, la cuestión prejudicial, además de ser un instrumento de uniformidad en la aplicación del Derecho mediante su interpretación, también permite juzgar, indirectamente, la compatibilidad del Derecho europeo derivado con los Tratados y hacer posible la unidad del ordenamiento europeo mediante la cuestión prejudicial de validez de los actos adoptados por las Instituciones. Es decir, es instrumento esencial de la justicia constitucional en la UE, pues permite la depuración del ordenamiento europeo y la decisión sobre la compatibilidad de los actos de los poderes públicos de los Estados con los Tratados.

La exigencia existencial de unidad de todo ordenamiento jurídico, impone al TJ el cargo del desarrollo jurisprudencial del ordenamiento europeo, en aras de la plenitud y coherencia del sistema jurídico comunitario (adjetivos necesarios para su unidad). EI TJ no sólo interpreta y juzga la validez del Derecho europeo, sino que también se ve obligado a colmar las lagunas que padezca tal sistema ${ }^{49}$, cumpliendo así, a través de este incidente procesal, una función cuasi-legislativa ${ }^{50}$.

${ }^{45}$ Parágrafo 11 del asunto CILFIT, C- 283/81 Srl. CILFIT and Lanificio di Gavardo Spa. V. Ministry of Health (1982).

${ }^{46}$ Asi lo expresó el TJ en el Asunto Hoffmann-La Roche, C-107/76 (1997), párrafo 5, según el cual el propósito del artículo 234 TCE es «to ensure that Community law is interpreted and applied in a uniform manner in all the Member States»y de este modo «the particular objective of the third paragraph is to prevent a body of national case law not in accord with the rules of Community law from coming into existence in any Member States».

${ }^{47}$ CRAIG. P., DE BURCA, G., EU Law. Texts, cases and materials, OUP, Oxford, 2008, segunda edición, p. 461.

${ }^{48}$ Ver en este sentido VALLE GÁLVEZ, A., "La especificidad del ordenamiento comunitario (comentario a los dictámenes 1/91 y 1/92 del TJCE sobre el Espacio Económico Europeo)", Revista de Instituciones europeas, Vol. 20, num. 1, 1993, pp. 155-194.

${ }^{49}$ AZPITARTE SÁNCHEZ, M., El Tribunal Constitucional ante el control del Derecho Comunitario derivado, Op. Cit. p. 112. El autor distingue cuatro utilidades diversas y convergentes en la cuestión prejudicial. En primer lugar como garantía de la unidad del ordenamiento comunitario, en segundo lugar como garantía de los derecho comunitarios, coadyuvando a la tutela judicial que concede el juez nacional («el juez nacional, inmerso en una relación de cooperación y no de jerarquía con el TJ, ha contribuido a la eficacia del derecho comunitario» p.113), en tercer lugar 
Por ello, el papel que adquiere el TJ a través del reenvío prejudicial es clave, no sólo para la uniformidad del Derecho europeo, sino también para construir el ordenamiento europeo, integrar los ordenamientos nacionales con el europeo, depurar el Derecho europeo y garantizar los derechos de los ciudadanos conforme a los Tratados. Es decir, a través de la cuestión prejudicial el TJ cumple una función jurisdiccional constitucional.

En conclusión, podría decirse que el planteamiento de cuestiones prejudiciales de interpretación o validez por el juez nacional al TJ cumple varias funciones constitucionales de enorme trascendencia, no sólo para la resolución del caso concreto en manos del juez nacional, sino para el propio funcionamiento del Derecho Europeo y su integración en los ordenamientos nacionales.

Primero, permite la eficacia uniforme de sus disposiciones a través de la determinación de su interpretación y alcance. Tiene por finalidad garantizar al Derecho comunitario en cualquier situación o circunstancia el mismo efecto en todos los Estados miembros de la Comunidad, otorgando al juez nacional un medio para eliminar las dificultades que pueda plantear la exigencia de dar al Derecho comunitario su pleno efecto en el marco de los respectivos sistemas jurisdiccionales de los Estados miembros ${ }^{51}$.

Segundo, es funcional a la unidad del Derecho europeo en tanto que ordenamiento jurídico. Concede unidad al ordenamiento europeo a través de la resolución de cuestiones sobre la legitimidad del Derecho derivado, concediendo coherencia al ordenamiento europeo y permitiendo la depuración formal de la legislación nacional y comunitaria ${ }^{52}$.

Tercero, permite al TJ observar las posibles lagunas del sistema mediante la interpretación cumpliendo una función de compleción del ordenamiento europeo, y al mismo tiempo, actualizando el significado de los Tratados.

garantiza la eficacia del derecho comunitario, unida a la tutela ordinaria del derecho comunitario llevada a cabo por los jueces ordinarios; y en cuarto lugar, distinguiendo la cuestión prejudicial de validez, como garantía de los derechos fundamentales.

50 BALAGUER CALLEJÓN, F., "Los Tribunales constitucionales en el proceso de integración europea" Op. Cit.

51 FERNÁNDEZ SEGADO, F., "El juez nacional como juez comunitario de derecho común. Las transformaciones dimanantes de ello", Op. Cit., pp. 115 y ss.

${ }^{52}$ Ver AZPITARTE SÁNCHEZ, M., El Tribunal Constitucional ante el control del derecho comunitario derivado, op. Cit., pp. 112-113. La cuestión prejudicial es también un poder de revisión extraordinario de la actuación de los jueces, ver Vg. el Asunto Khüne, STJ de 13 de enero de 2004, C- 453/00. 
Y en cuarto lugar, en relación con lo expuesto, es también un instrumento de garantía de los derechos de los particulares frente a los poderes públicos de los Estados $^{53}$, funciona como procedimiento de protección jurídica y judicial proporcionando a los justiciables una protección efectiva de los derechos e intereses que les reconoce el ordenamiento jurídico de la Unión Europea, ofreciéndoles la posibilidad de someter (indirectamente) sus litigios frente a los poderes públicos nacionales al examen del Tribunal de Justicia ${ }^{54}$.

\section{TIPOS DE CUESTIONES PREJUDICIALES: EL DIÁLOGO ENTRE}

\section{TRIBUNALES}

El procedimiento de reenvío prejudicial se encuentra en el artículo 19.3.b) del TUE (Tratado de la Unión Europea) y en el artículo 267 TFUE (Tratado de Funcionamiento de la Unión europea). Conforme al segundo apartado del artículo 267 TFUE, este procedimiento prejudicial de consulta al TJ es principalmente voluntario para el juez nacional. Se trata de una herramienta de ayuda para los jueces y magistrados nacionales en la interpretación o control de validez de las disposiciones europeas cuando son aplicadas o utilizadas para resolver un caso concreto dentro del Estado. La cuestión prejudicial ( de interpretación o validez) tiene una base cooperativa y voluntaria, puede ser presentada de forma discrecional por el juez cuando considera la existencia de una duda sobre la interpretación o la validez de la norma europea aplicable al caso concreto.

Sin embargo, conforme al apartado tercero del art. 267 TFUE, el reenvío prejudicial se convierte en una obligación en determinadas ocasiones. Cuando

${ }^{53}$ Cfr. AZPITARTE SÁNCHEZ, M., El Tribunal Constitucional ante el control del derecho comunitario derivado" op. Cit., pp. 112-113.

${ }^{54}$ Ver PESCATORE, "The doctrine of «Direct effect»: An infant Disease of Community Law", European Law Review, 1983, p. 155-164. Se hace imprescindible referirse a la Nota del Directorate General of internal policies of the Union, Policy Department: Citizen's Right and Constitutional affairs unit, respecto de "The relation between national courts and the European Court of Justice in the European Union Judicial system. Preliminary Rulings regimens according to articles 234 EC, 68 EC, 35 EU" de Febrero de 2007 (PE 378.291, Background note solicitada por el Comite de Asuntos jurídicos del Parlamento Europeo). Las funciones de la cuestión prejudicial son, desde esta perspectiva, tres según el Directorate: asegurar la uniformidad aplicativa mediante la cuestión de interpretación, asegurar la unidad del ordenamiento europeo y la coherencia del sistema jurisdiccional mediante la cuestión de validez surgida de disputas nacionales, y tercero, y más importante "it facilitates an acces to justice by making clear that Community law is to be applied not only by the ECJ but first at national courts level, thus enabling citizens to enforce their community Rights in national jurisdictions". Ver p. 12. 
surge una duda al juez nacional sobre la interpretación o la validez del Derecho europeo en el curso de un procedimiento nacional contra cuya sentencia no cabe ulterior recurso de Derecho interno. Es decir, cuando el juez que decide el caso es de última instancia. Para aquellos órganos jurisdiccionales nacionales que deban aplicar Derecho comunitario a los que se plantee una duda y "cuyas decisiones no sean susceptibles de ulterior recurso judicial de Derecho interno", dado que sus decisiones no son susceptibles de revisión posterior, la cuestión prejudicial se convierte en una obligación. Se trata así de prevenir la formación de cuerpos doctrinales contrarios a Derecho europeo ${ }^{55}$.

En este sentido el papel que desarrolla el TJ a través de la cuestión prejudicial se encuentra condicionado por el planteamiento del juez nacional. En pimer lugar, aunque en ocasiones su planteamiento sea obligatorio para el tribunal estatal, sigue siendo éste el encargado de redactar la cuestión, las dudas, y de ofrecer la información suficiente para que el TJ pueda situar la respuesta en un contexto. No sólo por el margen de discrecionalidad que permite al juez nacional a la hora de plantear una cuestión prejudicial al TJ, sino también porque el TJ sólo es competente para pronunciarse sobre la interpretación o la validez de una norma comunitaria a partir de los hechos que le proporcione el órgano jurisdiccional nacional, no le corresponde ni aplicar el Derecho comunitario al litigio principal ni apreciar los hechos del asunto principal, ni mucho menos apreciar la legitimidad del Derecho nacional ${ }^{56}$.

Por ello, la cuestión prejudicial es un procedimiento que se ha presentado por la doctrina como un "diálogo entre tribunales" ${ }^{\text {". }}$. Conforme al Tratado, el valor de la cuestión prejudicial reside en que es precisamente una cuestión iniciada por un juez nacional, que debe ser respondida por el TJ, y cuya respuesta retorna al juez nacional para que en base a ella pueda concluirse el procedimiento en sede nacional. También las Instituciones políticas de la Unión Europea han presentado

\footnotetext{
55 «The rationale for the duty to refer in art. 234 (3) is to prevent a body of national case law that is not in accordance with the EU law from being established in any member state", C-393/98 Ministero Publico and Gomes Valente v. Fazenda Pubblica (2001) , FJ. 17.

${ }^{56}$ Ver respectivamente SSTJ de 2 de junio de 1994 , asunto AC-ATEL Electronics, C-30/93; 10 de julio de 1980, asunto Giry y Guerlain, C.253/78, 1 y 3/79. Por todas STJ 9 de septiembre de 2003, asunto Consorzio Indusrie Fiamiferi, C- 198/01, FJ 62.

${ }^{57} \mathrm{Me}$ remito de ahora en adelante, para todo este capítulo a KILPATRICK, C., "The Future of remedies in Europe", en la obra colectiva del mismo nombre de KILPATRICK, C., NOVITZ, T., SKIDMORE, P., Hart, Oxford/Portland Oregon, 2000, pp. 1 y ss.
} 
la cuestión prejudicial como un procedimiento de cooperación y diálogo, es decir, basado en una relación entre jueces de carácter horizontal:

«La relación entre los tribunales nacionales y el TJ no es jerárquica. El sistema de la cuestión prejudicial se ha basado enteramente en la cooperación y el diálogo entre cortes nacionales y TJ, que no es una corte de apelación sino, más bien, un "tribunal especial" que delibera sólo cuando es requerido para ello. La referencia a través de la cuestión prejudicial es, en esencia, un diálogo entre el tribunal nacional que dirime "la acción principal", que es el único tribunal plenamente conocedor del asunto, y el tribunal comunitario - el TJ - que es el único capaz de asegurar una interpretación uniforme del Derecho comunitario " ${ }^{58}$.

En principio, la cuestión prejudicial es un instrumento de cooperación entre tribunales que supone una división de funciones entre órganos jurisdiccionales en interés de la interpretación y aplicación uniforme del Derecho comunitario en todos los Estados miembros ${ }^{59}$. Tal división de funciones permite el llamado diálogo jurisdiccional. Verdaderamente se encuentran no pocas cuestiones prejudiciales planteadas por jueces nacionales que se inspiran en un verdadero ánimo de cooperación y división del trabajo, modelo con el que los tribunales conciben al TJ como un tribunal especializado en que buscar apoyo para resolver los llamados «hard cases», este espíritu atiende al contenido literal del Tratado y del artículo 267 TFUE, es el que más se ajusta al Derecho positivo ${ }^{60}$.

Sin embargo, en la práctica el reenvío prejudicial no siempre se inspira en tal cooperación. El propio ánimo que lleva a los tribunales nacionales al planteamiento de la cuestión prejudicial se puede ver condicionado por las diferentes posturas que se tomen ante la integración, llegando a hacerse usos interesados del artículo 267 TFUE $^{61}$. Así, por ejemplo, se han observado determinados usos de la cuestión

${ }^{58}$ Nota requerida por el Comité de Asuntos jurídicos del Parlamento Europeo y realizado por la Unidad de Derechos de los ciudadanos y asuntos constitucionales de febrero de 2007. PE 378.29,

59 Asunto C- 244/80, Foglia C. Novello (no2) (1982). Ver también acerca de la separación de funciones Asunto C- 30/93, AC-ACTEL Electronics Vertriebs (1994), párrafo 16.

60 "The cooperation of national courts is a sine qua non for the success of the preliminary reference procedure and, consequently, the very development of the Community legal order. As a matter of fact, legal integration and the implementation of ECJ case law also rely on the willingness of national courts to refer cases to the ECJ» Informe del Directorate general Internal Policies of the Union requerido por el Comité de Asuntos Jurídicos del Parlamento Europeo, de febrero de 2007, PE 378.29.

${ }^{61}$ Los modelos que a continuación se indican son fruto de la investigación realizada por RAMOS ROMEU con una muestra completa de las cuestiones prejudiciales planteadas por los órganos jurisdiccionales españoles en el periodo de tiempo desde la adhesión del Estado Español a las CC.EE (1986) hasta el año 2000 inclusive. Ver RAMOS ROMEU, F., "Law and politics in the application of EC law: Spanish Courts and the ECJ 1986-2000", CMLR, n. 43, 2003, pp.395-421. №. 42 | p. 69 - 119 | JAN - ABR 2014 
prejudicial que la configuran como una estrategia de poder frente a otros poderes internos, ocasiones en las que el juez nacional invoca al TJ para legitimar su ejercicio de poder en el contexto doméstico, por ejemplo, para arrogarse el control de la legislación nacional frente a tribunales superiores internos ${ }^{62}$. En otros casos parece que los tribunales, al decidir sobre el reenvío de la cuestión, trataran de proteger el interés nacional, influenciándose según el entorno político, y observando más a las instancias políticas que al TJ para guiarse ${ }^{63}$. En ocasiones, incluso, se han observado situaciones en las que los tribunales internos parecen librar batallas jurídicas entre sí utilizando al TJ como forma de legitimar sus decisiones. Este último es el caso, por ejemplo, del Tribunal Supremo español (TS) que en la mayoría de sus salas parece renunciar a la cooperación con el TJ en la aplicación del Derecho europeo considerando que éste afecta a su posición de preeminencia en el sistema jurisdiccional interno. En estas situaciones, podría decirse que el TS trata de impedir una concepción del instrumento prejudicial como un procedimiento «cuasi federal» de revisión de las decisiones de los tribunales nacionales ${ }^{64}$.

Estas situaciones en las que se olvida la base dialéctica y cooperativa del procedimiento no suponen una cuestión trivial o de simples matices prácticos. Puesto que la decisión del planteamiento de la misma corre por exclusiva cuenta

En un sentido similar v. ALTERN, K., Establishing the supremacy of the European Law, OUP, Oxford, 2001, pp. 39 y ss.

${ }^{62}$ Ver la STJ de 16 de enero de 1974, asunto Rheinmühlen-Düsseldorf, C-166/73. En este sentido ver las Conclusiones del AG Cruz Villalón de 10 de junio de 2010, en el asunto Elchinov, C173/09. Es el caso de la versión neo- funcionalista de la cuestión prejudicial, RAMOS ROMEU, V., cit. y ALTERN, K., cit. Ver también SARMIENTO, D., "Las interpretaciones estratégicas del derecho comunitario y la crisis de la doctrina del acto claro", www.danielsarmiento.es/pdf/interpretaciones estrategicas.pdf, ultima consulta 13 de octubre de 2008.

${ }^{63}$ Este modelo es llamado por RAMOS ROMEU «modelo realista», "law and politics...". Op. Cit. Ya en los años 80 la doctrina española identificaba los problemas derivados de la actitud del juez nacional frente a la cuestión prejudicial, así PELÁEZ MARÓN consideraba que "nada garantiza que dicho organismo identifique sus propios intereses con los de la Comunidad" en ID, "Ámbito de la apreciación prejudicial de validez de los actos comunitarios", Revista de las instituciones europeas, 1985 , p. 758.

${ }^{64}$ Este modelo es llamado «intercourts competition» RAMOS ROMEU, "law and politics...". Op. Cit. Ver con más profundidad y centrado en la relación entre el TS español y el TJ a SARMIENTO, D., "La Cuestión prejudicial comunitaria y el Tribunal Supremo", en prensa. Ver también ID, "De Gorrones y jueces: Comentario a la Sentencia del Tribunal Supremo de 17 de enero de 2006", en http://www.danielsarmiento.es/pdf/gorrones jueces.pdf, última consulta 14 de octubre de 2008. En ambos trabajos se ponen de manifiesto datos alarmantes, como que el TS desde 1986 ha planteado (hasta la última actualización del trabajo a noviembre de 2006) un total de 17 cuestiones prejudiciales de las cuales 15 fueron enviadas por la sala Tercera de lo Contencioso administrativo, un número bajísimo si se compara con otros Estados. 
del juez o tribunal nacional. Dado que es competencia del tribunal nacional evaluar la relevancia de la disposición comunitaria en la disputa planteada ante él, y debido a que, en principio, el juez nacional decide discrecionalmente si debe o no plantear la referencia prejudicial ${ }^{65}$, e incluso cuando el planteamiento de la cuestión es un imperativo (apartado tercero del art. 267) corresponde exclusivamente al juez nacional determinar el contenido y relevancia de la pregunta planteada ${ }^{66}$; la decisión de plantear o no la cuestión y los términos de la misma pueden, por sí mismos, condicionar la uniformidad en la aplicación del Derecho europeo y quebrar su naturaleza de ordenamiento supranacional. Pueden dar lugar a una aplicación diversa en los Estados miembros, y pueden, por tanto, dar lugar a que los ciudadanos de unos estados disfruten de más o menos derechos que los de otros.

Para evitar esta discrecionalidad el TJ volverá a desarrollar algunos elementos del Derecho europeo que contribuirán a una "verticalización" encubierta de las relaciones con el juez nacional. Ello, como trataré de exponer brevemente, contribuye a observar al TJ como una auténtica jurisdicción constitucional. Estos elementos son la "doctrina del acto claro" y la objetivación de las condiciones de acceso de los ciudadanos a la jurisdicción del TJ.

\section{LA OBJETIVACIÓN DE LAS CONDICIONES DE PLANTEAMIENTO DE LA CUESTIÓN PREJUDICIAL POR EL JUEZ NACIONAL.}

7.1 La cuestión prejudicial de interpretación: la doctrina CILFIT o doctrina del acto claro

Frente al peligro que supone que el juez nacional no plantee correctamente la cuestión prejudicial, el TJ ha desarrollado una doctrina en la que establece los

\footnotetext{
65 Asunto C-348/89, Mecanartec. Chefe do serviço da Conferência Final da Alfândega (1991), párrafo 47. En esta decisión se dirime principalmente sobre la discrecionalidad del tribunal nacional para decidir en qué momento exacto del procedimiento es más adecuado el planteamiento de la cuestión.

${ }^{66}$ Asuntos acumulados C- 297/88 y C- 197/89, Dzodzi c. Estado Belga (1990)
} 
límites entre la cooperación judicial voluntaria y la obligación de planteamiento: la doctrina del acto claro ${ }^{67}$.

La doctrina del Acto claro trata de zanjar la discusión sobre si es obligatorio para el juez nacional plantear siempre y en todo caso la cuestión prejudicial sobre la interpretación del Derecho europeo ${ }^{68}$.

En 1981, la Corte de Casación italiana planteó al TJ una cuestión prejudicial $^{69}$ en la que preguntaba si, dado que se trataba de un órgano jurisdiccional estatal de última instancia, se encontraría, en cualquier caso, obligada por imperativo europeo a suspender el procedimiento y plantear cuestión de interpretación sobre el Derecho europeo al TJ, incluso cuando la interpretación del precepto comunitario fuese "tan evidente" que debía descartarse la posibilidad de concebir una duda interpretativa ${ }^{70}$.

El TJ, atendiendo a la utilidad del procedimiento prejudicial ${ }^{71}$, dictará la Sentencia CILFIT. En primer lugar considerará que la obligación de planteamiento

\footnotetext{
${ }^{67}$ La doctrina del "acte claire" trae origen de una antigua doctrina francesa. Surgió en una Sentencia de la Cour de Cassation de 13 de mayo de 1824 siendo posteriormente desarrollada por Laferriere en 1896. Se refería al reparto de poderes entre el ejecutivo y el judicial en orden a la interpretación de los Tratados internacionales, estableciéndose que, siendo el ejecutivo el único poder competente para dirigir las relaciones internacionales, los tribunales debían mostrar una gran reserva en lo concerniente a la interpretación de los tratados. Ver en este sentido FERNÁNDEZ SEGADO, F., "El juez nacional como juez comunitario europeo de Derecho común", op. Cit., p..p. 58 y ss. Esta doctrina fue proyectada sobre el ámbito europeo con la paradigmática sentencia del Conseil d'Etat francés de 19 de junio de 1964.

${ }^{68}$ BARNARD, C., y SHARPSTONE, E., "The changing face of article 177 EC...", op. cit., p. 1108. Como acertadamente consideró Catherine BARNARD «tanto si se acepta sabiamente que la cuestión prejudicial es un instrumento de cooperación judicial entre los tribunales nacionales y el TJ, como si se observa como un instrumento "cuasi-federal" de revisión de la compatibilidad del Derecho nacional con el Derecho europeo, el mecanismo sólo funciona de forma efectiva si las reglas del juego han sido claramente entendidas por ambos".

${ }^{69}$ Sentencia de 6 de octubre de 1982 del TJ (C-238/81) del asunto Srl. Cilfit y Lanificio di Gavardo $\mathrm{SpA}$ c. Ministerio de salud italiano.

70 Según el Gobierno italiano, la evidencia en la interpretación del Derecho comunitario permitiría excluir la exigencia de plantear una cuestión prejudicial al Tribunal de Justicia. Este argumento se sustenta en el reconocimiento que el TJ había realizado años antes de la doctrina del "acto claro" en la sentencia Da Costa. Años después confirmada en la STJ de 16.07.1974, en el asunto Rheinmühlen/Einfuhr und Vorratsstelle gertreide, C-166/73, en la que el TJ había declarado en el FJ 4 párrafo $3^{\circ}$ que "Considerando que de estos razonamientos resulta que una norma de Derecho nacional, que vincule a los órganos jurisdiccionales que no resuelven en última instancia a las valoraciones jurídicas efectuadas por el órgano jurisdiccional superior, no puede privar a aquéllos de la facultad de someter al Tribunal de Justicia cuestiones de interpretación del Derecho comunitario al que se refieran tales valoraciones jurídicas; que la situación sería distinta si las cuestiones formuladas por el órgano jurisdiccional que no resuelve en última instancia fueran materialmente idénticas a las ya planteadas por el órgano jurisdiccional que resuelve en última instancia" (la cursiva es mía).

71 Tanto en el asunto Da Costa, cit., como en el asunto Rheinmühlen/Einfuhr und Vorratsstelle gertreide, cit., fue claramente establecida la utilidad del procedimiento prejudicial. En este último asunto se estableció, por ejemplo, en sus FF.JJ 2 y 3 que el anterior artículo 177 resultaba
} №. 42 | p. 69 - 119 | JAN - ABR 2014 
de cuestión prejudicial de interpretación «se inserta en el marco de la colaboración, instituida con el fin de garantizar la correcta aplicación y la interpretación uniforme del Derecho comunitario en el conjunto de los Estados miembros, entre los órganos jurisdiccionales nacionales, en su calidad de Jueces competentes para la aplicación del Derecho comunitario, y el Tribunal de Justicia ${ }^{72}$ ». En este marco de colaboración, y desde la naturaleza cooperativa del procedimiento, el TJ considera que son los órganos jurisdiccionales estatales de última instancia quienes «disponen de la (...) facultad de apreciación (...) acerca de si es necesaria una decisión sobre una cuestión de Derecho comunitario para poder emitir su fallo». Por lo tanto, en tanto que procedimiento de colaboración entre tribunales que depende de la discrecionalidad del juez nacional: «(a)quellos órganos jurisdiccionales no están obligados, por tanto, a remitir una cuestión de interpretación de Derecho comunitario suscitada ante ellos si la cuestión no es pertinente, es decir, en los supuestos en los que la respuesta a dicha cuestión, cualquiera que fuera, no podría tener incidencia alguna en la solución del litigio ${ }^{73}$ ». Concretamente, reenviando al asunto Da Costa, el TJ afirmará que tiene el mismo efecto que el reenvío prejudicial el que «pued(a) derivar de la jurisprudencia ya asentada del Tribunal de Justicia que hubiera resuelto la cuestión de Derecho de que se trata, cualquiera que sea la naturaleza de los procedimientos que dieron lugar a dicha jurisprudencia, incluso en defecto de una estricta identidad de las cuestiones debatidas ${ }^{74}$ ».

Por lo tanto, ante la existencia de un "precedente judicial" del TJ los órganos estatales de última instancia pueden no plantear la cuestión prejudicial y resolver por sí mismos, especialmente cuando la cuestión sea materialmente idéntica a otra ya planteada y resuelta por el TJ. Esta es la doctrina del acto claro o acto aclarado.

\footnotetext{
"esencial para preservar el carácter comunitario del Derecho instituido por el Tratado, tiene por objeto garantizar que, en cualesquiera circunstancias, este Derecho produzca el mismo efecto en todos los Estados de la Comunidad; que, si bien tiene por objeto evitar divergencias en la interpretación del Derecho comunitario que han de aplicar los órganos jurisdiccionales nacionales, pretende también garantizar esta aplicación ofreciendo al órgano jurisdiccional nacional un medio para eliminar las dificultades que pueda suscitar la exigencia de dar plenos efectos al Derecho comunitario en el marco de los sistemas jurisdiccionales de los Estados miembros; que, por consiguiente, cualquier laguna en el sistema así establecido cuestionaría la eficacia misma de las disposiciones del Tratado y del Derecho comunitario derivado; que desde esta perspectiva deben apreciarse las disposiciones del artículo 177 (...)",

${ }^{72}$ Ver FJ 7, STJ 6.10.1982, C-283/81.

${ }^{73}$ Ibídem.

74 Idem, FJ 13.
} 
Aunque a primera vista puede parecer que el TJ flexibiliza los términos del artículo 267 TFUE, sin establecerá unos requisitos para que el juez pueda determinar cuando el acto normativo europeo es lo suficientemente claro. El límite a la obligación de reenvío prejudicial debe encontrar algunos requisitos que derivan de «las características del Derecho comunitario y de las dificultades particulares que presenta su interpretación ${ }^{75} »:$ 1. que «la correcta aplicación del Derecho comunitario pued(a) imponerse con tal evidencia que no deje lugar a duda razonable alguna sobre la solución de la cuestión suscitada» ${ }^{76}$. 2. que «el órgano jurisdiccional nacional debe llegar a la convicción de que la misma evidencia se impondría igualmente a los órganos jurisdiccionales nacionales de los otros Estados miembros, así como al Tribunal de Justicia» ${ }^{77}$. 3. que debe tenerse en cuenta que «los textos de Derecho comunitario están redactados en varias lenguas y que las diversas versiones lingüísticas son auténticas por igual; por tanto, la interpretación de una disposición de Derecho comunitario supone una comparación de las versiones lingüísticas ${ }^{78}$ ». 4. que «debe observarse a continuación que, incluso en caso de exacta concordancia de las versiones lingüísticas, el Derecho comunitario utiliza una terminología propia ${ }^{79}$ », y por lo tanto «cada disposición de Derecho comunitario debe ser situada en su contexto e interpretada a la luz del conjunto de las disposiciones de ese Derecho, de sus finalidades y de su grado de evolución en la fecha en la que debe hacerse aplicación de la disposición de que se $\operatorname{trata}^{80} \gg$.

Esta decisión del TJ ha podido tener, incluso, un efecto contrario al pretendido incialmente. Si de una lectura literal de la misma se desprende una configuración de la cuestión prejudicial como herramienta de colaboración y procedimiento de diálogo ajeno a cualquier estructuración de las relaciones entre tribunales en términos jerárquicos, no falta doctrina que considere que el TJ, mediante la confirmación de la doctrina del acto claro, se ha atribuido mayor poder que a sus colegas nacionales ${ }^{81}$.

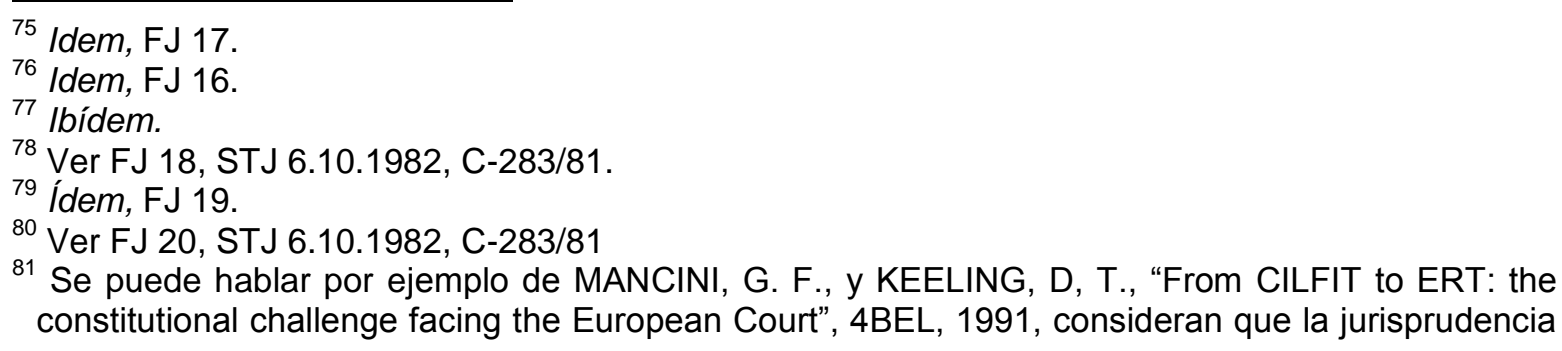


Efectivamente, con la sentencia Cilfit se asienta, por un lado, el valor definitivo de las decisiones del TJ como precedente judicial, con todo lo que ello supone desde las características propias del "precedent" típico de la familia jurídica del Common Law ${ }^{82}$ respecto de los jueces nacionales. Por otro lado, las condiciones "leoninas ${ }^{83 "}$ que deben cumplir los jueces nacionales, para asegurarse de que la interpretación del Derecho europeo que tienen por cierta se muestra de forma tan "evidente" que pueden prescindir de la obligación del planteamiento prejudicial, son prácticamente insalvables. No basta con que el juez nacional se someta al precedente judicial establecido por el TJ, sino que además, como ha señalado RUIZ JARABO, exigen que el juez nacional emprenda «un estudio empírico de los ordenamientos jurídicos de los otros veinticuatro Estados miembros para lograr el convencimiento psicológico de que todos y cada uno de sus homólogos confirmarían la correcta aplicación de la norma europea ${ }^{84}{ }$, estudio empírico que necesitaría de la confrontación lingüística de las 27 traducciones

CILFIT es una estrategia por parte del TJ de "give and take" pp. 1-10. También ARNULL. A., "The use and abuse of article 177", CMLR, 52, 1989, pp. 622-626.

${ }^{82}$ Así lo señala RASMUSSEN, que considera que la autoridad del TJ se ve incrementada al establecerse de forma generalizada el valor de precedente de la jurisprudencia del TJ. Ver RASMUSSEN, H., "The European Court's Acte Clair Strategy in C.I.L.F.I.T.; Or, Acte Clair, of Course! But What Does it Mean?", European Law Review, n. 10, 1984, p. 252. Ciertamente, el valor del precedente de las sentencias judiciales, como creación propia del sistema jurídico de la familia del Common law, situaría al TJ en una posición parangonable a la de un legislador judicial. Sobre la naturaleza del precedente ver DUXBURY, N., The nature and authority of precedent, Cambridge, Cambridge Univesity Press, 2008, espec., pp. 37 y ss; y pp. 122 y ss; Sobre el acercamiento del sistema europeo hacia parámetros propios del Common law ver ÖHLINGER, T., "La influencia del Derecho comunitario sobre la legislación y la judicatura. Notas a un proceso de «americanización» del Derecho europeo", Anuario Iberoamericano de Justicia Constitucional, n. 8, 2004, pp. 361 y ss. Sobre la actitud del TJ como un cuasi-legislador, o incluso como un sustituto del constituyente ver BALAGUER CALLEJÓN, F., "Los Tribunales constitucionales en el proceso de integración europea", op. cit.

${ }^{83}$ Así se expresa SARMIENTO, D., "Las interpretaciones estratégicas del Derecho comunitario y la doctrina del acto claro", op. Cit.

${ }^{84}$ Así se expreso RUIZ- JARABO COLOMER en las Conclusiones del asunto Gaston Schul, C461/03, presentadas el 30 de junio de 2005: "Además, la sentencia advirtió de las exigencias interpretativas inherentes a la naturaleza propia del Derecho comunitario, ya que: por un lado, utiliza términos y conceptos autónomos, que no siempre coinciden con los equivalentes en los sistemas nacionales; por otro lado, cada disposición ha de situarse en su contexto y entenderse a la luz del conjunto normativo en el que se inserta, de su finalidad y de su grado de evolución. La sentencia CILFIT llamó la atención asimismo sobre el carácter plurilingüístico del Derecho comunitario, redactado en diferentes idiomas, actualmente en veinte, con el expreso reconocimiento de autenticidad a todas las versiones. En suma, el test propuesto era inviable en el momento de su formulación, pero en la realidad del año 2005 resulta disparatado, pues no responde a la preocupación histórica con la que se adoptó, la de reconducir los excesos de la teoría del acto claro en que habían incurrido algunos tribunales de última instancia de los Estados miembros". 
oficiales de la jurisprudencia y los textos normativos de la UE. Unas condiciones, que como el propio Abogado General ha señalado son "disparatadas".

Siendo estrictos, y con la ventaja del paso del tiempo, debería decirse que mediante la jurisprudencia Cilfit ni se ha configurado una colaboración leal entre tribunales, ni se ha conseguido que los tribunales nacionales puedan ser controlados cuando no plantean la cuestión prejudicial. Todo lo contrario, podría decirse que la articulación de las relaciones entre jueces nacionales y TJ encuentran nuevos, y más complejos, puntos de tensión ${ }^{85}$.

Con esta afirmación podría argumentarse de forma definitiva que la cuestión prejudicial no puede plantearse en términos verticales, como una revisión previa de las decisiones europeas del juez nacional por el TJ. Sin embargo esta visión no parece compartirse por la mayoría de la doctrina. Especialmente a la luz de la configuración de la cuestión prejudicial de validez y de la jurisprudencia Foto-Frost.

\section{2 la cuestión prejudicial de validez y las doctrinas Foto-Frost}

Si con la doctrina Cilfit se viene a decir que cuando un juez nacional de última instancia deba aplicar una norma de Derecho europeo cuya interpretación no ofrezca dudas razonables puede prescindir del planteamiento de la cuestión prejudicial de interpretación, en el asunto Foto-Frost se trazará una importante diferencia respecto de las dudas sobre la validez de las normas europeas.

En la sentencia del TJ en el asunto Foto-Frost, de 22 de octubre de 1987, el tema nuclear es, como dirá el Abogado General Mancini en las conclusiones del asunto, "uno de los más espinosos que este Tribunal de Justicia haya tenido nunca que afrontar ${ }^{86 "}$. Un órgano jurisdiccional alemán plantea una cuestión prejudicial preguntando al TJ si los Jueces inferiores de los Estados miembros, es decir, aquellos cuyas decisiones sí son susceptibles de ulterior recurso de Derecho interno, pueden pronunciarse de oficio sobre la validez de los actos comunitarios.

${ }^{85}$ Como ha señalado SARMIENTO, D., "Las interpretaciones estratégicas...", Cit., respecto de los jueces "Freelander": "El paso del tiempo nos ha mostrado que la doctrina CILFIT ha sido un error. La ambigüedad de la Sentencia, que por un lado establece una exención a la que luego acompaña de unas condiciones imposibles de cumplir, no ha hecho más que incentivar la negativa a plantear la cuestión prejudicial".

${ }^{86}$ Ver el apartado $4^{\circ}$ de las Conclusiones del Abogado General Mancini presentadas el 19 de mayo de 1987, en el asunto C-314/85. 
Si como hemos señalado el artículo 267 TFUE establece que la cuestión prejudicial tiene carácter voluntario para aquellos jueces o tribunales estatales inferiores, se plantea la cuestión de si esta discrecionalidad es sostenible en el caso de que la duda que se plantea al juez nacional verse sobre la validez de un acto europeo conforme a los Tratados.

Si los Tratados no distinguen entre la cuestión prejudicial de interpretación y de validez del Derecho europeo, entonces, podría pensarse que conforme al texto del artículo 267 TFUE sólo los jueces cuyas decisiones no sean susceptibles de ulterior recurso jurisdiccional están obligados a plantear la cuestión de validez al TJ, así que los jueces de primera instancia deberían poder controlar la validez de los actos de las Instituciones comunitarias, cuando tengan que aplicarlas, conforme a los Tratados. Un control de validez del Derecho europeo en sede estatal ${ }^{87}$. Por el contrario, puede entenderse que conforme a lo dispuesto en los arts. 263 y 264 TFUE el TJ tiene el monopolio exclusivo de control de legalidad de los actos adoptados por las Instituciones, pues de permitirse el control de validez por los jueces nacionales se estaría introduciendo "un factor destructivo" de la uniformidad aplicativa del Derecho europeo, puesto que la determinación de la "invalidez de una norma tiene como consecuencia necesaria también su desaplicación a nivel interno. Por tanto, conforme a este último argumento "el Juez nacional que albergue dudas sobre la validez de la norma comunitaria deberá suspender el procedimiento y dirigirse al Tribunal de Justicia ${ }^{88 "}$ mediante el respectivo planteamiento de cuestión prejudicial, quepan o no quepan ulteriores recursos de Derecho interno.

EI TJ, mediante sentencia de 22 de octubre de 1987, afirmará que: “los órganos jurisdiccionales nacionales no son competentes para declarar por sí

\footnotetext{
87 Ver entre otras las Sentencias dictadas entre 1966 y 1968 por la Sala Segunda del Verwaltungsgericht de Frankfurt-am-Main: de 12 de diciembre de 1966, no AZ II/2 986/66 y n이/2 987/66, el 23 de agosto de 1967, no AZ II/2 E 24/67, el 13 de diciembre de 1967, no AZ II/2 E 79/67, el 22 de mayo de 1968, no AZ II/2 E 20/68 y el 27 de noviembre de 1968, no AZ II/2 E 33/68. Así como la sentencia del Finanzgericht de Munich de 11 de septiembre de 1985. Como transcribe el AG Mancini en las Conclusiones del asunto Foto-Frost, "basta recordar que los autores del Tratado CEE tenían delante de los ojos el modelo del artículo 41 del Tratado CECA en el que se sanciona la competencia exclusiva del Tribunal de Justicia. Habrían podido reforzar dicho principio; no lo hicieron, en cambio, precisamente porque se inspiraban en una orientación distinta que consistía en promover a los Jueces nacionales al rango de verdaderos Jueces comunitarios confiando en su aplicación del derecho respectivo y por consiguiente también en la no aplicación de los actos considerados inválidos", esta idea se sostiene en la intención, de nuevo, de aliviar de carga de trabajo al TJ. Ver apartado 4ํ de las Conclusiones, cit.

${ }^{88}$ Ver Apartado $5^{\circ}$ de las Conclusiones, cit.
} 
mismos la invalidez de los actos de las instituciones comunitarias ${ }^{89 "}$. Concretamente argumentará que "la coherencia del sistema exige que la facultad de declarar la invalidez del mismo acto, si se plantea ante un órgano jurisdiccional nacional, esté reservada asimismo al Tribunal de Justicia ${ }^{90 " . ~ P o r ~ o t r o ~ l a d o, ~ e l ~ T J ~}$ apela a la exigencia de uniformidad en la aplicación del Derecho europeo, y más aun, su propia unidad en tanto que ordenamiento jurídico:

"las competencias reconocidas al Tribunal de Justicia por el artículo 177
[267 TFUE] tienen esencialmente por objeto garantizar una aplicación
uniforme del Derecho comunitario por los órganos jurisdiccionales
nacionales. Esta exigencia de uniformidad es particularmente imperiosa
cuando se trata de la validez de un acto comunitario. (...) las divergencias
entre los órganos jurisdiccionales nacionales de los Estados miembros en
cuanto a la validez de los actos comunitarios pueden llegar a
comprometer la misma unidad del ordenamiento jurídico comunitario y
perjudicar la exigencia fundamental de la seguridad jurídica ${ }^{91 " .}$.

En conclusión, cuando se trata de dirimir sobre la validez o legitimidad del Derecho europeo, ni siquiera el juez de primera instancia (al que pueden rectificar posteriores sedes jurisdiccionales mediante recursos de Derecho interno) puede dejar de aplicar una norma de Derecho europeo por considerarla inválida (conforme al propio ordenamiento comunitario) sin una previa decisión por parte del TJ. La duda del juez sobre la validez de una disposición europea exige siempre el reenvío prejudicial al TJ.

Se observa entonces una bifurcación del artículo 267 TFUE. La cuestión prejudicial no se configura, en relación a las competencias del juez nacional, de igual modo cuando éste duda sobre la interpretación de una disposición europea o sobre su validez. En el primer caso no está obligado a plantear la cuestión a menos que no quepa posterior recurso jurisdiccional, e incluso en este caso, la cuestión no es imperativa atendiendo a la doctrina del acto claro. Sin embargo, cuando la duda recae sobre la validez todos los órganos jurisdiccionales nacionales deben plantear la cuestión prejudicial. Esta segunda versión de la cuestión prejudicial de validez altera las competencias del juez

\footnotetext{
${ }^{89}$ Ver FJ 20 de la STJ Foto-Frost, cit.

90 Ídem FJ 17.

${ }^{91}$ Ver FJ 15 de la STJ Foto-Frost, cit. Este mismo argumento ha sido repetido en un asunto más reciente acerca de la cuestión prejudicial de validez: "esta exigencia de uniformidad es particularmente imperiosa cuando se trata de la validez de un acto comunitario. Las divergencias pueden comprometer la misma unidad del ordenamiento jurídico comunitario y perjudicar la exigencia fundamental de seguridad jurídica", ver STJ de 10 de enero de 2006, asunto The Queen, a instancia de International Air Transport Association y European Low Fares Airline Association contra Department for Transport, (IATA vs ELFAA), C-344/04, FJ 27.
} 
nacional como juez comunitario y la propia naturaleza cooperativa de la cuestión prejudicial. Efectivamente, puede parecer que el juez nacional pierde el margen de discrecionalidad que le otorgaba la doctrina del acto claro respecto del reenvío prejudicial, y es que no parece ser lo mismo una mala interpretación del Derecho europeo, que una completa inaplicación del mismo por considerarlo inválido, esta última sería contraria al principio de primacía $^{92}$, si no es expresamente declarada por el TJ.

Unido al epígrafe anterior podemos decir que el TJ realiza una interpretación muy particular de la cuestión prejudicial tal y como aparece redactada en los Tratados. Por un lado, cuando a un juez nacional, en el marco de un procedimiento interno, se le plantee una duda sobre la interpretación de disposiciones de Derecho europeo aplicables al caso, éste estará obligado a plantear la cuestión prejudicial siempre que sea juez de última instancia en el ámbito nacional, y sólo podrá separarse de la obligación de reenvío prejudicial cuando exista un precedente y se cumplan unas condiciones tales que, prácticamente, hacen imposible asumir la doctrina del acto claro. Por otro lado, cuando a un juez nacional se le plantee una duda sobre la validez de una disposición europea que deba ser aplicada en el marco de un procedimiento jurisdiccional estatal, entonces, está absolutamente obligado a suspender el procedimiento y plantear la cuestión prejudicial al TJ, siempre, aunque contra sus sentencias quepan ulteriores recursos de Derecho interno.

\section{8. el planteamiento de la Cuestión PREjudicial Y LA PROGRESIVA "VERTICALIZACIÓN" DE LAS RELACIONES ENTRE LOS JUECES NACIONALES Y EL TJ}

Tanto en Cilfit como en Foto-Frost, el TJ sí parece mantener, a priori, que la cuestión prejudicial se plantea exclusivamente cuando juez nacional así lo considera de oficio. En la primera decisión el TJ dejaba claro que el reenvío prejudicial no constituía un recurso disponible para las partes: "no basta con que

92 En referencia a la cuestión prejudicial de validez será en la STJ Factortame en el asunto C213/1989, de 19 de junio de 1990, en la que el TJ hace referencia a la doctrina Simmenthal como fundamento esencial para responder a la cuestión sobre las competencias del juez nacional para inaplicar normas nacionales durante el periodo transcurrido entre el planteamiento de la cuestión prejudicial y la resolución. FJ. 18. 
una parte sostenga que la cuestión suscita una duda para que el juez [nacional] se vea obligado a plantearla93". Así mismo lo consideraba el Abogado General en las conclusiones del asunto Foto-Frost al afirmar que "nada obligará a nuestro magistrado a preguntar a este Tribunal de Justicia si una parte le solicita que no aplique un acto y considera que sus motivos van a ser rechazados. Aquí, la facultad que le reconoce el [... art. 267] es plenamente operante; y dicho dato [...] excluye precisamente la reducción de su papel a una mera "transmisión de documentos ${ }^{94 " . ~ T a m b i e ́ n ~ e n ~ e l ~ a s u n t o ~ F o t o-F r o s t ~ e l ~ T J, ~ e n ~ c o n s o n a n c i a ~ c o n ~ s u ~}$ doctrina anterior sobre la naturaleza cooperativa de la cuestión prejudicial, comienza la fundamentación de su sentencia dejando claro este extremo:

"Estos órganos jurisdiccionales pueden examinar la validez de un acto comunitario y, si no encuentran fundados los motivos de invalidez que las partes alegan ante ellos, desestimarlos concluyendo que el acto es plenamente válido. En efecto, al actuar de este modo, no enjuician la existencia del acto comunitario... En cambio, no tienen la facultad de declarar inválidos los actos de las instituciones comunitarias ${ }^{95,}$

La importancia de esta afirmación reside en que el TJ, a priori, confirma su doctrina según la cual la cuestión prejudicial (sea de interpretación sea de validez) no constituye un recurso disponible para las partes de un litigio suscitado ante un juez nacional, y en consecuencia, no basta con que una parte alegue que el litigio suscita una cuestión de validez de Derecho comunitario para que el órgano jurisdiccional de que se trate esté obligado a considerar que se plantea una cuestión en el sentido del artículo 267 TFUE $^{96}$. Decimos, y subrayamos, que se confirma esta visión de la cuestión prejudicial sólo a priori, porque que la cuestión prejudicial no fuese en un principio concebida como un recurso abierto a las partes, ello no significa que la alegación por una de las partes en el litigio de una duda de validez no pueda conducir, y empujar al juez nacional, a la suspensión del procedimiento en espera de una decisión por parte del TJ para resolver el caso concreto en sede nacional ${ }^{97}$. La clave se encuentra en el carácter

\footnotetext{
${ }^{93}$ Ver FJ 9 de la STJ Cilfit, cit.

${ }^{94}$ Ver el apartado 6 de las Conclusiones del Abogado General Mancini en el asunto Foto-Frost, cit.

${ }^{95}$ Ver FF.JJ 13 y 14 de la STJ Foto-Frost, cit.

${ }^{96}$ Doctrina consolidada que puede observarse más recientemente en la STJ IATA vs. ELFAA, cit., FJ 28

97 Ibídem, ver FJ 32: "cuando un órgano jurisdiccional cuyas decisiones puedan ser objeto de un recurso judicial de derecho interno estima que uno o varios de los motivos de invalidez de un acto comunitario alegados por las partes, o en su caso planteados de oficio están fundados, debe suspender el procedimiento y plantear al TJ una cuestión prejudicial" (la cursiva es propia).
} 
de mayor subjetividad u objetividad que contenga la "duda" de interpretación o de validez que se suscita ante el juez.

Conforme a los Tratados puede decirse que, como regla general, la decisión sobre la oportunidad del reenvío prejudicial es una decisión autónoma del juez. La cuestión prejudicial se plantearía de oficio por el juez nacional cuando se le suscitara, en el marco de un proceso nacional, una duda sobre la interpretación o la validez de una disposición europea necesaria para la resolución del caso. La cuestión clave se sitúa entonces en el tipo de duda, en sus límites: qué es y qué no es la «duda razonable» que impulsa el planteamiento de la cuestión prejudicial. La forma en que se configura esa "duda" del juez es la clave del inicio del reenvío al TJ.

En Cilfit y Foto-Frost el TJ trata de construir los elementos que deben configurar la duda del juez. En ambas sentencias se limita el ámbito de apreciación de la duda por el juez nacional, estableciéndose algunos criterios. En Cilfit, mediante la doctrina del acto claro, se concretan las situaciones en las que el juez nacional puede prescindir de plantear la cuestión prejudicial aun estando obligado a ello. Esta posibilidad se establece mediante la adopción de criterios que permiten determinar la inexistencia de una duda razonable sobre la interpretación del Derecho europeo. Sin embargo, se ha acabado diciendo sobre los criterios Cilfit que la doctrina más realista los considera como prácticamente insalvables. Siendo estrictos es muy difícil que el juez pueda cumplir satisfactoriamente todos y cada uno de los elementos de discernimiento que le permitirían prescindir del reenvío, por lo que la doctrina del acto claro termina reforzando la obligación de reenvío prejudicial del juez de última instancia.

En el caso de la cuestión de validez ya observamos que la decisión FotoFrost imposibilita que el juez nacional prescinda jamás del reenvío, incluso cuando la decisión del juez nacional es susceptible de ulterior recurso de Derecho interno. Según esta sentencia el juez nacional no puede nunca dejar de aplicar el Derecho europeo por considerarlo inválido sin una previa decisión del TJ.

Debe concluirse que objetivar los criterios del reenvío y reforzar su planteamiento por el juez supone alterar el reparto de competencias que originariamente se establecía en el procedimiento de la cuestión prejudicial, un 
procedimiento, no lo olvidemos, que originariamente se configuraba como colaboración horizontal entre tribunales.

Esta objetivación de la cuestión prejudicial, en mi opinión, sitúa en el centro el rol de los particulares incursos en el proceso nacional. Traslada parte de la responsabilidad del juez nacional sobre el planteamiento de la cuestión prejudicial a las partes del litigio. Las partes en el litigio nacional pueden solicitar el planteamiento de la cuestión prejudicial. Aunque la regla general es que la cuestión prejudicial "no constituye un recurso disponible para las partes de un litigio suscitado ante un juez nacional, y en consecuencia no basta con que una parte alegue que el litigio suscita una cuestión de validez [o de interpretación] del Derecho comunitario para que el órgano jurisdiccional de que se trate esté obligado a considerar que se plantea una cuestión" en el sentido del artículo 267 TFUE; sin embargo, la jurisprudencia establecida refuerza una visión distinta.

Cuando el particular invoca ante el juez nacional una disposición de Derecho comunitario que puede componer la norma aplicable al caso concreto, ésta deberá aplicarse siempre y de forma inmediata por el juez nacional (conforme a los principios de eficacia directa y primacía). Si las partes alegan que existe alguna duda sobre la verdadera eficacia de la disposición europea en el litigio, su sentido o su aplicabilidad, entonces sólo el juez nacional de última instancia es competente para decidir la realidad de la duda y plantear la cuestión prejudicial, haciendo que el asunto llegue al TJ. Según la doctrina del acto claro, cuando el juez considere que realmente se suscita una duda, y la duda verse sobre una cuestión materialmente idéntica a otra ya planteada y resuelta por el TJ, este juez podrá separarse de la obligación de reenvío atendiendo al precedente. Pero junto a este criterio del precedente, además, el TJ establecía unos requisitos "disparatados", por los que el juez nacional siempre se vería obligado al planteamiento a no ser que "no dejase lugar a duda razonable alguna sobre la solución de la cuestión suscitada" y y esta solución se impusiese igualmente con total convicción "a los órganos jurisdiccionales nacionales de los otros Estados miembros, así como al Tribunal de Justicia"99, y todo ello una vez que se hubiesen comparado las 27 versiones lingüísticas de la disposición europea, y se hubiese interpretado "a la luz

\footnotetext{
${ }^{98}$ STJ Cilfit, cit. FJ 16.

99 Íbidem.
} 
del conjunto de las disposiciones del Derecho comunitario ${ }^{100 " . ~ E s ~ d e c i r, ~ l a ~}$ alegación por el particular de una duda sobre la interpretación de la disposición europea invocada, empujaría al juez nacional al planteamiento de la cuestión, a menos que el TJ se hubiese posicionado sobre un asunto materialmente idéntico y nuestro juez (políglota) hubiese examinado la jurisprudencia de los tribunales de los otros 27 Estados miembros. Por eso, se ha considerado por parte de la doctrina, que la "duda razonable" se ha objetivado en la jurisprudencia Cilfit hasta tal punto que el deber de reenvío se hace prácticamente obligatorio cuando la duda sobre la interpretación de la disposición europea es alegada por una de las partes $^{101}$.

Por otro lado, en la cuestión prejudicial de validez se refuerza aún más la objetivación de la obligación. Y es que si en este caso la función del reenvío de validez del TJ es la imprescindible unidad del ordenamiento europeo, esta finalidad no puede depender del exclusivo criterio del juez ${ }^{102}$. El deber del juez se convierte en un deber objetivo, puesto que la finalidad - la unidad del ordenamiento europeo y su depuración- así lo impone, algo que excede a la mera discrecionalidad del juez ordinario. Como señala el TJ en el asunto Foto-Frost, el juez nacional debe o rechazar los motivos de invalidez que alegan las partes (algo que objetivamente sólo podría hacer por la existencia de una declaración de validez previa del TJ) y aplicar la norma europea o plantear siempre la cuestión prejudicial. Y en este deber objetivo la discrecionalidad del juez ordinario debería quedar anulada bastando que la duda sea planteada por una de las partes ${ }^{103}$.

La objetivación de los términos de la cuestión prejudicial podría derivar en dos planteamientos. (A) Por un lado, la jerarquización del mecanismo, de ser un incidente procesal entre tribunales relacionados horizontalmente y con una eficacia bilateral, pasaría a convertirse en un procedimiento jerarquizado y multilateral. (B)

\footnotetext{
${ }^{100}$ Ver FJ 20, STJ 6.10.1982, C-283/81

${ }^{101}$ Como ejemplo concreto sobre situaciones en las que la duda interpretativa es alegada de forma inicial por una de las partes en el litigio y ello empuja al juez a reenviar cuestión prejudicial al TJ puede verse la STJ Elchinov, cit.

${ }_{102}$ Ver en este sentido DE BURCA, G., y WEILER, J. H. H., The European Court of Justice, op. cit., También en estos términos AZPITARTE SÁNCHEZ, M., El Tribunal Constitucional ante el control del Derecho comunitario derivado, cit.

${ }^{103}$ En este sentido se expresa el AG Capotorti en las Conclusiones de 13 de julio de 1982, presentadas en el asunto Cilfit, cit.
} 
Por otro lado, la objetivación de la duda conduciría a una apertura del mecanismo hacia las partes del litigio.

(A) Han sido CRAIG y DE BURCA los principales valedores en doctrina de la idea del proceso de verticalización del mecanismo de la cuestión prejudicial. Consideran que esta jurisprudencia enfatiza el hecho de que el TJ se sitúa en una posición superior respecto de los tribunales nacionales. Todo ello desde la perspectiva de que mediante sus sentencias el TJ ha "enrolado" a los tribunales nacionales en la tarea de controlar el cumplimiento y la aplicación del Derecho europeo. Se percibe como una parte central de la amplia jerarquía judicial europea, en cuya cúspide se sitúa el TJ. Las relaciones se transforman de manera, además multilateral, puesto que las respuestas prejudiciales del TJ influyen (como un precedente) "de facto or de iure" en las demás cortes nacionales ${ }^{104}$.

(B) La objetivación del carácter de la duda podría conducir a la cuestión prejudicial a convertirse en un deber objetivo del juez, a su generalización, momento en el que las alegaciones de las partes adquieren un papel esencial, pues con la simple alegación podría fundamentarse la duda que conduzca al juez nacional al reenvío ante el TJ. Desde esta perspectiva debe entonces destacarse una idea que nutre el contenido de la cuestión prejudicial: puede considerarse que el reenvío prejudicial se encuentra directamente relacionado con la invocación de

\footnotetext{
${ }^{104}$ Ver CRAIG. P., DE BURCA, G., EU Law. Texts, cases and materials, OUP, Oxford, 2008, segunda edición. p., 461. No comparte completamente esta idea WEILER: "As a matter of fact, this new line of cases probably represents (...) a departure of the European Court from an ethos of presenting itself as primus inter pares and maintaining a zone of autonomy for national jurisdiction, even at the price of non-uniformity in the application of Community law, in order to achieve the prize of increased effectiveness, even at the cost of a potential tension in the critical relationship between the European Court and national courts. And this impression seems not to be eased by the assurances of the President of the Court, speaking in his extra-judicial capacity but on behalf of all its members, that "from our perspective, the relationship between the ECJ and national constitutional courts is one of cooperation. It is certainly true that EU law may enjoy supremacy over national law and that, most of the times, EU law may also be directly applicable in Member States' legal orders. However, that does not mean that national supreme courts, and especially national constitutional courts, are institutionally subordinate to the ECJ. On the contrary, the judicial architecture of the European Union and the Member States' judiciaries must be viewed as parallel systems, coexisting within the same supranational structure, and having, in principle, their own proper areas of jurisdiction". Ver WEILER, J. H. H., "The Least-Dangerous Branch: A Retrospective and Prospective of the European Court of Justice in the Arena of Political Integration" en ID. The Constitution of Europe: Do the New Clothes Have a New Emperor? and Other Essays on European Integration, Cambridge University Press, Cambridge, 1999, pp. 188222. En un sentido muy similar al de Craig y De Burca ver SKOURIS, V., "The Position of the European Court of Justice in the EU Legal Order and its Relationship with National Constitutional Courts", conferencia presentada en el Bled, Slovenia, el 30 de septiembre de 2004. Disponible en http://www.usrs.si/media/zbornik.pdf
} №. $42 \mid$ p. 69 - $119 \mid$ JAN - ABR 2014 
pretensiones fundadas en Derecho europeo por las partes, es decir, las alegaciones de las partes en el litigio nacional pueden impulsar el reenvío al TJ.

Esta última afirmación es coherente con la idea, mantenida por el TJ, del juez nacional como órgano competente para la garantía de la tutela judicial efectiva de los derechos concedidos por el ordenamiento comunitario a los ciudadanos (primacía y eficacia directa). Precisamente para imponer esta tarea, el TJ, desde las Sentencias Costa y Van Gend en Loos, utilizó el argumento del procedimiento de la cuestión prejudicial, tal y como se había considerado en los Tratados, como fundamento del deber del juez nacional de tutelar los derechos concedidos por el ordenamiento comunitario a los ciudadanos, al mismo tiempo, que configuraba la obligación de aquel de garantizar la primacía y eficacia directa de las disposiciones comunitarias en su aplicación.

Esta posibilidad que acabamos de expresar ha hecho que la doctrina considere si el TJ no ha buscado desarrollar un particular rol constitucional por sí mismo como una «corte de los ciudadanos» ${ }^{105}$ donde los ciudadanos pueden acudir (por medio de un incidente procesal) solicitando la revisión de la validez de los actos de las Instituciones cuando les son aplicables y solicitando la tutela de sus derechos.

\section{LA PETICIÓN DE LA CUESTIÓN PREJUDICIAL POR LOS} CIUDADANOS: “JUDICIAL REVIEW” Y TUTELA JUDICIAL EFECTIVA DE LOS DERECHOS DE LOS CIUDADANOS

Creo que pueden encontrarse elementos de relación entre el mecanismo de la cuestión prejudicial y la tutela judicial efectiva de los derechos de los particulares concedidos por el ordenamiento europeo. Esta relación tendría el mismo fundamento que la progresiva objetivación del mecanismo del reenvío prejudicial.

\footnotetext{
${ }^{105}$ Como un ejemplo más de la doctrina que no ha compartido desde el inicio la idea de que la cuestión prejudicial no sea realmente un procedimiento accesible a las partes del proceso, me remito a ALTERN, K., y SLAUGHTER, A. M., The European Courts and national Courts Doctrine and jurisprudence, Hart publishing, OUP, Oxford, 1988. También DE BURCA, G., y WEILER, J. H. H., The European Court of Justice, OUP, 2001, pp 7 y ss., cuestionan si el TJ no ha buscado desarrollar un particular rol constitucional por sí mismo como una «corte de los ciudadanos» o una asamblea participativa, pero concluyen que respecto de la percepción expresada por algunos de sus jueces vocales en sus escritos extra-judiciales, el TJ ha resistido ante las varias rutas procesales ofrecidas como opciones ante él para transformarse en una forma más abierta de este tipo.
} 
La obligación del juez nacional de plantear cuestión prejudicial se configura poco a poco como un deber objetivo en situaciones concretas, de forma que se abre a las alegaciones por las parte en el litigio nacional, que pueden forzar el deber de reenvío. Este protagonismo de las partes del litigio parece ser coherente con las pretensiones del sistema de tutela de derechos de los Tratados, puede configurar a la cuestión prejudicial como un nuevo elemento para la garantía de derechos de los particulares, si tenemos en cuenta que, en los Tratados, existen muy pocos mecanismos que legitimen a los particulares para acudir al TJ.

Los Tratados Europeos han previsto procedimientos en los que se legitiman a los ciudadanos como partes activas de un proceso ante el TJ, pero esta legitimación ha sido, desde el principio, muy limitada. Esta escasa legitimación se observa particularmente en los mecanismos de judicial review del Derecho europeo. Es el caso, por ejemplo, del recurso directo de anulación del artículo 263 párrafo cuarto del TFUE. Conforme a ese procedimiento de control de validez abstracto del Derecho europeo, en principio, "toda persona física o jurídica podrá interponer recurso, en las condiciones previstas en los párrafos primero y segundo, contra los actos de los que sea destinataria o que le afecten directa e individualmente y contra los actos reglamentarios que la afecten directamente y que no incluyan medidas de ejecución."

Los particulares pueden interponer recurso ante el TJ pretendiendo un análisis de validez de los actos de las Instituciones comunitarias que les perjudiquen, sin embargo se exige un requisito previo: el particular debe verse "afectado directa e individualmente" por la medida. La afectación directa supone que la disposición comunitaria debe surtir efectos directos en la situación jurídica del particular, debe ser el propio acto el que afecte a la situación jurídica de los interesados, sin que esta se produzca por otros actos de aplicación ${ }^{106}$. Respecto de la afectación individual, debe entenderse que el particular, para interponer recurso directo contra una disposición europea, debe ser directamente el destinatario de la disposición. Esta afectación individual en el caso de determinadas fuentes normativas como las Decisiones no entraña excesivas dificultades pues, conforme al artículo 288 párrafo $4^{\circ}$ "la decisión será obligatoria

\footnotetext{
${ }^{106}$ Ver STJ 13 de mayo de 1971, asunto International Fruit Company, C-41/70 a 44/70, FFJJ 15-22; STJ 5 de mayo de 1998, C-386/96, asunto Societé Louis Dreyfus. FJ 43.
} 
en todos sus elementos. Cuando designe destinatarios, sólo será obligatoria para éstos". Sin embargo en el caso de que sea un Reglamento europeo el que vulnere derechos de los particulares garantizados en los Tratados, al tener tal fuente "un alcance general" (288 primer párrafo) la legitimidad de los ciudadanos para acudir directamente ante el TJ disminuye. Frente a estos actos de alcance general la jurisprudencia de Luxemburgo ha dispuesto que el particular sólo estará legitimado para interponer recurso de nulidad cuando la norma europea le atañe debido a ciertas cualidades que le son propias o a una situación de hecho que le caracterice en relación con cualesquiera otras personas y, por ello, les individualiza de una manera análoga a la del destinatario ${ }^{107}$. Este último requisito ha sido interpretado de manera restrictiva, y en determinados casos el hecho de que se pudiera determinar el número o incluso la identidad de los afectados por un reglamento no ha logrado ampliar la legitimación para interponer el recurso directo ante el $\mathrm{TJ}^{108}$.

Las restricciones a los particulares para acceder al judicial review por parte del TJ han sido muy criticadas por la doctrina ${ }^{109}$ conforme avanzaba el proceso de integración. Y ciertamente la jurisprudencia del TJ en este sentido resultaba incoherente con el papel que los jueces de Luxemburgo han desempeñado en la construcción de la "Comunidad de Derecho" o el reconocimiento de los derechos fundamentales en la UE ${ }^{110}$.

Por ello, el TJ, a través de su jurisprudencia parece haber operado un cambio en la naturaleza de la cuestión prejudicial. Paradigmáticas resultan las

\footnotetext{
107 STJ de 15 de julio de 1963, Plaumann/Comisión, 25/62, p. 25. STJ de 18 de mayo de 1994 , asunto Codorníu, C-309/89. STJ Más recientemente, STJ 7 de diciembre de 2010, T-49/07, asunto Sofiane Fahas, FJ 33,

108 STJ 17 de junio de 1980, C-789,790/79, asunto Calpak, FJ 9. STJ 15 de junio de 1993, C213/91, Albertal Sat Ltda, FJ 20. Ver GARCÍA LOYGORRI, A., "En el horizonte de la tutela judicial efectiva, el TJCE supera la interpretación restrictiva de la legitimación activa mediante el uso de la cuestión prejudicial y la excepción de ilegalidad", Documentos de Trabajo del Instituto de Estudios Europeos, n.5, 2004.

${ }^{109}$ Por ejemplo ARNULL, A., "Private applicants and the action for annulment under article 173 of the Treaty", CMLR, n. 32, 1995, pp. 44 y ss. MANCINI, G., "The role of the supreme courts at the national and international level: a case study of the Court of Justice of the European Communities " en YESSIOU-FALTSI, P., The role of the supreme courts at the national and international level, OUP, 1998, pp.421 y ss. LENAERTS, K., "The legal protection of private parties under the EC Treaty: a coherent and complete system of judicial review?", en Scritti in onore di Giuseppe Federico Mancini, Vol. II, 1998, pp.591 y ss. CRAIG, P., y DE BURCA, G., EU Law: Texts, cases and materials, OUP, 2003, pp. 487 y ss. CHALMERS, D., et alt., European Union Law, Cambridge University Press, 2007, pp. 420 y ss.

${ }^{110}$ Me remito a la primera parte de esta tesis.
} 
conclusiones del Abogado General Jacobs en el asunto Unión de Pequeños Agricultores (UPA) ${ }^{111}$, asunto en el que se intuirá un cambio jurisprudencial.

En este caso, la UPA acudió al TJ reclamando su legitimidad para interponer recurso de anulación contra las medidas de ejecución de la OCM del aceite que excluían de las subvenciones comunitarias diversos cultivos. Frente a la doctrina sobre la afectación directa, y dado que el acto impugnado revestía la forma de reglamento, la UPA alegó que de determinarse su falta de legitimidad para interponer tal recurso, se podría vulnerar su derecho a la tutela judicial efectiva. Derecho reconocido por el ordenamiento comunitario como principio general $y$ recogido en el propio Convenio Europeo de Derechos Humanos ${ }^{112}$.

EI TJ aunque niega la legitimidad a los particulares para platear recurso directo de nulidad, en la sentencia UPA afirmará que

\begin{abstract}
"procede recordar que la Comunidad Europea es una comunidad de Derecho cuyas instituciones están sujetas al control de conformidad de los actos que adoptan con el Tratado y con los principios generales del Derecho, de los que forman parte los derechos fundamentales. Por consiguiente los particulares deben poder disfrutar de una tutela judicial efectiva de los derechos que les confiere el ordenamiento jurídico comunitario... 113". "Pues bien, el Tratado, mediante sus artículos 173 y 184 (actualmente 277 TFUE), por una parte, y mediante su artículo 177 (268 TFUE) ha establecido un sistema completo de vías de recurso y de procedimientos destinado a garantizar el control de la legalidad de los actos de las instituciones, confiando dicho control al juez comunitario. En dicho sistema, las personas físicas o jurídicas que debido a los requisitos de admisibilidad previstos en el artículo 173 párrafo cuarto (263TFUE), del Tratado, no puedan impugnar directamente actos comunitarios de alcance general, tiene la posibilidad, según los casos, de invocar la invalidez de
\end{abstract}

\footnotetext{
${ }^{111}$ Conclusiones presentadas el 21 de marzo de 2002, en el asunto UPA, C-50/00.

112 Ver STJ Jhonston, cit.: En esa decisión, se dispone en el FJ 19 que "corresponde a los Estados miembros garantizar un control jurisdiccional efectivo para que se respeten las disposiciones aplicables de Derecho europeo y las de la legislación nacional destinadas a garantizar la posibilidad del ejercicio de los derechos previstos en la directiva". Como señala CARANTA, R., "Judicial protection against member states: a new ius commune takes shape", CMLR, 32, 1995, 703-726, ambas sentencias caracterizan el principio de tutela judicial efectiva como una obligación de los EE. MM. De asegurar que los derechos concedidos por el derecho comunitario pueden hacerse valer ante los tribunales nacionales, y consecuentemente, como un principio que permite a los jueces nacionales desplazar las disposiciones nacionales que hacen la afirmación de tales derechos imposible o la dificultan extremamente, p. 706. En este asunto principal, UPA, EI Abogado General Jacobs, concluirá que para evitar una vulneración del derecho a la tutela judicial efectiva, en su opinión, debería establecerse un cambio en la jurisprudencia del TJ, considerándose que "una persona resulta individualmente afectada por un acto comunitario si, debido a sus circunstancias particulares, el acto lesiona o puede lesionar sus intereses de manera sustancial. Ver el apartado 60 de las Conclusiones citadas. Poco tiempo antes, el TJ había flexibilizado sus criterios en base al derecho a la tutela judicial efectiva en la STJ de 2 de abril de 1998, asunto Greenpeace, C-321/95. Las interpretaciones de Jacobs en el asunto UPA, aun cuando no serán escuchadas por el TJ en este caso, sí fueron recogidas por el TPI en la STPI de 3 de mayo de 2002, asunto Jegó-Quéré, T-177/01.

${ }^{113}$ Ver STJ UPA FFJJ 37 a 41.
} №. 42 | p. 69 - 119 | JAN - ABR 2014 
tales actos bien de manera incidental ante el juez comunitario, en virtud del artículo 184 del Tratado, bien ante los órganos jurisdiccionales nacionales, e instar a estos órganos, que no son competentes para declarar por sí mismos la invalidez de tales actos a que soliciten un pronunciamiento del Tribunal de Justicia sobre este extremo por medio de la cuestión prejudicial”114.

En conclusión, el TJ repetirá una idea ya asentada en su jurisprudencia: corresponde a los Estados miembros prever un sistema de vías de recurso y de procedimientos que permita garantizar el respeto del derecho a la tutela judicial efectiva $^{115}$. Pero lo sorprendente es que se apoye en la cuestión prejudicial para identificar el sistema completo de las vías de recurso y procedimientos destinadas a tal efecto. Como se observa, y en lo que aquí nos interesa, el TJ considerará que en el sistema "completo de vías de recurso" que contemplan los Tratados, la cuestión prejudicial de validez reemplaza a los mecanismos directos de los que disponen los ciudadanos ante el $\mathrm{TJ}^{116}$.

\footnotetext{
${ }^{114}$ Ver STJ UPA FFJJ 37 a 41.

${ }^{115}$ Así se ha expuesto en diferentes ocasiones, estableciéndose el principio de la tutela judicial efectiva como principio general del Derecho comunitario, por ejemplo, en STJ Ministerio Público y Gomes Valente, C-393/98. Este principio ha sido incluido en los propios Tratados. Conforme al artículo 19.1 TUE: Los estados miembros establecerán las vías de recurso necesarias para garantizar la tutela judicial efectiva en los ámbitos cubiertos por el Derecho de la Unión. Ver al respecto CRAIG, P., y DE BURCA, Text, cases and materials, OUP, 2000.

${ }^{116}$ Así lo cree también y lo expresa el AG RUIZ JARABO en las conclusiones de 28 de abril de 2005 en el asunto Atzori et alt., C- 346, 529/03. En este sentido en doctrina ver DE BURCA, G., y WEILER, J. H. H., consideran que el TJ ha elevado a la cuestión prejudicial a la función equivalente del recurso por incumplimiento y el recurso directo. Cfr. The European Court of Justice, cit., p. 28. En este sentido, para PESCATORE, aunque sea al juez nacional a quien corresponde observar la pertinencia de la pregunta y formular el contenido de la cuestión prejudicial, siempre le conviene consultar a las partes, lo que muestra "que el juez normalmente está precedido en su exploración por las partes y por los abogados de estas. La historia del recurso prejudicial muestra que, en realidad, el éxito del artículo 177 se debe a la sensibilización de las partes, por lo que se refiere a los derechos conferidos por el ordenamiento comunitario, a la iniciativa de los abogados y a la comprensión por el juez de la problemática planteada ante él". PESCATORE, P., "la interpretación del derecho comunitario por el juez nacional", Revista de Instituciones Europeas, Vol. 23, no 1, pp. 7-32. En un sentido similar MANCINI, F., KEELING, D., "From CILFIT to ERT: the constitutional challenge facing the European Court", cit., cuando expresan que Francovich dio al artículo 169 TCEE y al poder de revisión sobre la legislación nacional uñas y dientes más incisivos que aquellos inventados por los autores del Tratado de Maastricht. También DUTHEIL DE LA ROCHĖRE, J., y PERNICE, I., "FIDE 2002 Eu Law and National Constitutions", WHI Paper 17/02, pp. 21 y ss. Adelantamos ahora algunas citas sobre la relación entre los ciudadanos y los Estados miembros a través de los procedimientos jurisdiccionales dirigidos a la aplicación y al cumplimiento del derecho comunitario ("remedies"). Ver por ejemplo EILMANSBERGER, T., "The relationship between Rights and remedies in EC Law: in search of the Messing link", CMLR, n. 41, 2004, pp. 1199-1246; CURTIN, D., y MORTELMANS, K., "Application and Enforcement of Community Law by the Member States: actors in search of a third generation script", en CURTIN, D., y HEUKELS, T., (eds.), Institutional dynamics of European integration. Essays in honour of Henry G. Schermes. Vol. II, Martins Nijhoff Publishes, Dordrecht, Boston/London, 1994, pp. 423-466; más en general y completo KILPATRICK, C., NOVITZ, T., y SKIDMORE, P., The future of remedies in Europe, Oxford, Hart, 2000.
} №. $42 \mid$ p. 69 - $119 \mid$ JAN - ABR 2014 
En mi opinión, la clave de esta sentencia del TJ es la idea de la Unión Europea como Comunidad de Derecho. Conforme a la Resolución del Parlamento Europeo de 9 de julio de 2008 la visión de la UE como "una comunidad fundada y basada en el Estado de Derecho; que el Derecho comunitario es letra muerta si no es aplicado adecuadamente por los Estados miembros, incluyendo los jueces nacionales, que son, por lo tanto la piedra angular del sistema judicial de la Unión Europea y que desempeñan un papel central e indispensable para la creación de un ordenamiento jurídico único europeo". Este valor del juez nacional como juez comunitario sobre el que se ha ido construyendo "todo un arsenal de poderesdeberes del juez nacional frente al Derecho interno incompatible con el comunitario $^{117 ",}$, debe recordarse, se construye sobre dos piezas básicas. Por un lado, un ordenamiento autónomo que debe ser integrado en los ordenamientos nacionales y aplicado de manera uniforme: construido sobre el principio de primacía del Derecho europeo, el juez nacional debe desaplicar las disposiciones nacionales contrarias a Derecho europeo ${ }^{118}$. Por otro lado, un sistema de fuentes europeas que incorporan al ordenamiento nacional directamente disposiciones europeas, y que en consecuencia pueden ser invocadas ante los jueces nacionales como fundamento de pretensiones particulares (eficacia directa).

Ahora, se concretan dos obligaciones del juez nacional: la obligación del juez de reenvío al TJ, y la obligación del juez nacional de garantizar la tutela judicial efectiva de los particulares europeos. Estas obligaciones traen causa de la eficacia directa y la primacía del Derecho europeo, son los mecanismos esenciales de la construcción de la unidad del ordenamiento europeo, el mecanismo de la integración. La lógica de la cuestión prejudicial no es sino un instrumento de apoyo para el juez nacional al cumplir con su obligación de dar uniformidad al Derecho europeo al tiempo que tutela los derechos de los particulares.

Desde esta perspectiva, la cuestión prejudicial se convierte en procedimiento esencial del sistema de justicia constitucional europeo, pues permite depurar el ordenamiento europeo y el sistema en su conjunto, y además, posibilita la tutela de los derechos de los ciudadanos ante una instancia jurisdiccional común

${ }^{117}$ ALONSO GARCÍA, R., "Juez nacional como juez europeo a la luz del Tratado constitucional",

${ }_{118}^{\text {cit., }}$ STJ Tanja Kreil de 11 de enero de 2000, donde el TJ justifica la existencia de la primacía del Derecho europeo sobre el nacional en la necesidad existencial de no contravenir el carácter imperativo y la aplicación uniforme de Derecho comunitario, ver FJ 16. 
a todos los Estados mediante un procedimiento accesible, bajo ciertas condiciones, a los particulares. Es decir, la cuestión prejudicial se va abriendo poco a poco a una concepción cada vez más cercana a los procedimientos constitucionales de "judicial review" y de recurso de amparo de derechos.

\section{EL DESARROLLO DE LA SOCIEDAD ABIERTA DE LOS} INTÉRPRETES CONSTITUCIONALES Y DEL DERECHO PROCESAL CONSTITUCIONAL EN LA UE

Las cuestiones que suscita la tutela judicial efectiva del Derecho europeo, la cuestión prejudicial y el acceso de los ciudadanos, requieren de un análisis más profundo del que aquí se pueda realizar sobre la jurisprudencia del TJ y la jurisprudencia constitucional de los Tribunales de los Estados miembros.

Sin embargo, en este artículo he tratado de exponer las bases esenciales que nos permitan constatar la existencia de un sistema de Justicia constitucional en la UE, en construcción y continuo desarrollo. No es un sistema acabado, por supuesto, pues en la UE no existe una verdadera Constitución en sentido formal ni un verdadero Tribunal Constitucional europeo que permita la integración estructural del Derecho europeo y el Derecho de los Estados. Pero sí se observa que, en el centro del sistema de integración, se hace cada vez más necesario repensar las estructuras jurídicas de la UE en términos de justicia constitucional. Pues ese es el destino de la integración si se pretende que conserve su naturaleza de ordenación supranacional del poder en garantía de los derechos de los ciudadanos.

En este sistema supranacional destacan los principios de primacía y eficacia directa, como elementos esenciales que determinan la naturaleza de la integración y de la Unión Europea: como Comunidad de Derecho. Estos principios no sólo establecen relaciones entre el ordenamiento europeo y los ordenamientos nacionales, sino que, además, permiten reconocer a los ciudadanos de los Estados como sujetos de Derecho europeo. Los ciudadanos pueden invocar pretensiones subjetivas fundadas en Derecho europeo, y pueden hacerlas valer ante los tribunales nacionales. Es decir, se nutren de derechos de naturaleza europea que deben adquirir eficacia a nivel interno. 
La caracterización de los ciudadanos estatales como sujetos de Derecho europeo exige del reconocimiento de mecanismos jurisdiccionales que permitan el reconocimiento y la protección de sus derechos frente a los poderes públicos. Como determina el TJ (STJ UPA) "los particulares deben poder disfrutar de una tutela judicial efectiva de los derechos que les confiere el ordenamiento jurídico comunitario", por ello los Tratados han "establecido un sistema completo de vías de recurso y de procedimientos destinado a garantizar el control de la legalidad de los actos de las instituciones, confiando dicho control al juez comunitario".

Entre este sistema de vías de recurso adquiere un lugar central la cuestión prejudicial. Se convierte en instrumento clave de la relación entre tribunales nacionales y TJ, contribuyendo a la integración del Derecho europeo en el momento de mayor trascendencia, la aplicación de las normas europeas y nacionales a casos concretos por los poderes públicos nacionales. Por otro lado, la invocación de normas europeas por los ciudadanos ante los jueces nacionales puede permitir que los ciudadanos, a través del planteamiento de la cuestión prejudicial, accedan a la jurisdicción del TJ. Situación que después de la objetivación de las condiciones del reenvío prejudicial operado por el TJ (Cilfit, Foto-Frost) convierten a este procedimiento en instrumento esencial de la Justicia constitucional en la UE.

La cuestión prejudicial, pese a ser un mecanismo originariamente entendido en términos de diálogo horizontal entre tribunales y de colaboración, debe estudiarse desde su naturaleza constitucional. Por un lado, se convierte en un elemento clave en la interacción entre el espacio constitucional interno de los Estados y el espacio constitucional de la UE, através de los jueces nacionales y el TJ, por lo que contribuye al desarrollo del Derecho constitucional europeo. Pero por otro lado, y desde una visión amplia, la cuestión prejudicial, al objetivar las condiciones para su planteamiento y permitir el acceso de los ciudadanos al TJ, puede contribuir a la participación de los ciudadanos en la construcción del sistema, en la interpretación del Derecho europeo en casos concretos y el desarrollo hermenéutico de los Tratados en clave constitucional.

Desde esta perspectiva se puede observar la cuestión prejudicial como un elemento que contribuye a reforzar la participación de la ciudadanía en el proceso de integración desde los postulados de las teorías de la "sociedad abierta de los 
intérpretes constitucionales" y el desarrollo del "Derecho procesal constitucional" expuestos por Peter HÄBERLE ${ }^{119}$.

Conforme a la doctrina de la Sociedad abierta se pretende «fortalecer al ciudadano, moverlo hacia el centro del Estado constitucional y su sociedad pluralista, y también frente a las competencias del Estado hiperfortalecidas, así como frente al señorío del mercado y de los partidos políticos que se establecen en no raras ocasiones con autosuficiencia. El pensamiento desde el ciudadano y su sociedad debe limitar y corregir el tradicional "pensamiento desde el Estado"120". Desde estos objetivos la teoría de la Sociedad abierta se traslada al ámbito de la jurisdicción constitucional, en el sentido en que «cada quien que vive una norma constitucional la co-interpreta en un sentido amplio, profundo», o en términos europeos, cada quién que invoca una norma europea (a través del principio de primacía y eficacia directa) ante la jurisdicción nacional, la co-interpreta, la concreta en un caso particular, y la desarrolla cuando fundamenta sobre ésta pretensiones subjetivas y derechos frente a la actuación del poder público.

Recuérdese que la cuestión prejudicial puede cumplir en ocasiones una función de recurso para las partes ante el TJ. Atendiendo a la teoría de la Sociedad abierta de los intérpretes constitucionales de HÄBERLE, el acceso de los particulares al TJ se ha convertido en la vía de escape de la presión provocada por la carencia de una verdadera Constitución en la UE, de modo que los ciudadanos, aun por vías jurídicas y no políticas, pueden terminar participando de la interpretación del Derecho y el desarrollo del proceso de integración como partes en un proceso jurisdiccional. La posibilidad que se presenta ahora, a un tiempo, en la cuestión prejudicial de personación de las partes ante el TJ puede suponer, desde el proceso, una «garantía del pluralismo y la participación» de los ciudadanos, pues, mediante la cuestión prejudicial como garantía de la uniformidad de la aplicación de las normas europeas, el ciudadano puede forzar el diálogo entre tribunales, contribuyendo, por un lado, al desarrollo del Derecho

\footnotetext{
119 HABERLE, P., "La Sociedad abierta de los intérpretes constitucionales. Una contribución para la interpretación pluraslita y 'procesal' de la Constitución”, Trad. Xavier Arzoz Santisteban, en Retos actuales del Estado Constitucional, Instituto Vasco de Administración Pública, Oñate, 1996, pp. 15-46.

${ }^{120}$ HÄBERLE, P., "La Jurisdicción Constitucional en la Sociedad Abierta” en FERRER MACGREGOR, E., ZALDIVAR LELO DE LA REA, A. (Coords.), La ciencia del Derecho procesal constitucional. Estudios en homenaje a Héctor Fix-Zamudio en sus cincuenta años como investigador del Derecho. Teoría general del Derecho procesal constitucional. México, UNAM, 2008, pp. 763-784.
} 
constitucional europeo en sentido amplio, y por otro lado, forzando que el propio TJ intervenga en su caso. En sede europea, el ciudadano podrá aportar una interpretación particular del Derecho originario europeo en igualdad de condiciones a los representantes de los Estados miembros y las Instituciones europeas.

La invocación del Derecho europeo en un caso concreto por los ciudadanos en sede nacional, contribuye, además, al desarrollo del "derecho procesal constitucional [europeo]" como «garantía del pluralismo y la participación». El ciudadano se convierte en sujeto esencial de la jurisdicción constitucional europea pues, contribuye a la depuración del ordenamiento europeo dotándolo de unidad, y al mismo tiempo encuentra un refugio jurisdiccional para revisar los planteamientos judiciales de los estados miembros y tutelar, en última instancia, sus pretensiones y derechos frente a los poderes públicos.

Desde esta perspectiva, la cuestión prejudicial, junto a los principios de eficacia directa y primacía, y el papel del ciudadano en el Derecho europeo, conforman elementos esenciales de un sistema de Justicia constitucional supranacional, que por supuesto debe seguir desarrollándose. 